\title{
Combined effects of climate, resource availability, and plant traits on biomass produced in a Mediterranean rangeland
}

\author{
Simon Chollet, ${ }^{1}$ Serge Rambal, ${ }^{1}$ Adeline Fayolle, ${ }^{1}$ Daniel Hubert,${ }^{2}$ Didier Foulquié, ${ }^{3}$ and Eric Garnier ${ }^{1,4}$ \\ ${ }^{1}$ CNRS, Centre d'Ecologie Fonctionnelle et Evolutive (UMR 5175), 1919 Route de Mende, 34293 Montpellier Cedex 5, France \\ ${ }^{2}$ INRA, Elevage des Ruminants en Régions Chaudes, 2 Place Viala, 34060 Montpellier Cedex 01, France \\ ${ }^{3}$ INRA, Domaine de La Fage, 12250 Roquefort, France
}

\begin{abstract}
Biomass production in grasslands, a key component of food provision for domestic herbivores, is known to depend on climate, resource availability, and on the functional characteristics of communities. However, the combined effects of these different factors remain largely unknown. The aim of the present study was to unravel the causes of variations in the standing biomass of plant communities using a long-term experiment conducted in a Mediterranean rangeland of Southern France. Two management regimes, sheep grazing and grazing associated with mineral fertilization, were applied to different areas of the study site over the past 25 years. Abiotic (temperature, available water, nutrients) and biotic (components of the functional structure communities) factors were considered to explain interannual and spatial variations in standing biomass in these rangelands.

Standing biomass was highly predictable, with the best model explaining $\sim 80 \%$ of variations in the amount of biomass produced, but the variation explained by abiotic and biotic factors was dependent on the season and on the management regime. Abiotic factors were found to have comparable effects in both management regimes: The amount of biomass produced in the spring was limited by cold temperatures, while it was limited by water availability and high temperatures in the summer. In the fertilized community, the progressive change in the functional structure of the communities had significant effects on the amount of biomass produced: the dominance of few productive species which were functionally close led to higher peak standing biomass in spring.
\end{abstract}

Key words: climate variability; dominance hypothesis; forage production; functional complementarity; functional structure of communities; grazing; interannual variation; nutrient and water availability; response and effect framework.

\section{INTRODUCTION}

Plant biomass production is a key component of ecosystem functioning, which drives other processes like litter decomposition, nutrient cycling, and secondary production (Chapin et al. 2002). In grasslands, primary production is known to be highly variable, both in space and time (Knapp and Smith 2001), and understanding the controls on this variability remains a central issue in ecology (e.g., Lemaire et al. 2011). Chapin et al. (2002) recognized that ecosystem properties depend both on "independent controlling variables" such as climate, parent rock material or time, and on "interactive controls" such as resources, modulators (temperature, $\mathrm{pH}$, and so on), or biotic communities.

Climate has long been identified as a primary factor controlling biomass production in grasslands. At a local scale, interannual variability of rainfall is generally weakly related to interannual variability of biomass

Manuscript received 23 April 2013; revised 25 July 2013; accepted 30 July 2013; final version received 29 August 2013. Corresponding Editor: D. A. Wardle.

${ }^{4}$ Corresponding author. E-mail: eric.garnier@cefe.cnrs.fr production (Lauenroth and Sala 1992, Briggs and Knapp 1995, La Pierre et al. 2011), and finer variables such as rainfall during periods critical to plant growth (La Pierre et al. 2011) or soil water available to the vegetation during these periods (Nippert et al. 2006, Muldavin et al. 2008) have been identified as critical variables. Temperature is another climatic factor assumed to explain interannual variations in biomass production (Sala et al. 1988), but it has been much less studied than rainfall. Interannual fluctuations of climate leading to variations in production may also have carryover effects, as plants can store carbohydrates in a given year and reuse them for growth in the following year (Jobbagy and Sala 2000, Oesterheld et al. 2001).

Beyond climate, grazing (Milchunas and Lauenroth 1993, Oesterheld et al. 1999) and nutrient availability (e.g., Duru et al. 1997, LeBauer and Treseder 2008) are additional factors controlling production in grasslands. These two factors tend to have opposite effects, since grazing generally induces a decrease in grassland production (discussed by Milchunas and Lauenroth 1993, Oesterheld et al. 1999), while nutrient addition mostly leads to increased biomass production (e.g., Gough et al. 2000, Crawley et al. 2005). In addition, 
grazing and nutrient availability have impacts on species richness, identity, and functional traits (see Cingolani et al. 2007, Díaz et al. 2007b for grazing, and Garnier and Navas 2011, Gaujour et al. 2012 for nutrients). There is now a growing consensus that these functional characteristics of species affect ecosystem properties, and biomass production in particular (e.g., Lavorel and Garnier 2002, Díaz et al. 2007a). Two broad, nonexclusive hypotheses, have been proposed to explain the effects of species traits on ecosystem properties: the "dominance," or biomass ratio hypothesis (Grime 1998), which states that these effects depend on the traits of the dominant species in the community; and the "niche complementarity" hypothesis (Petchey and Gaston 2006), which assumes that ecosystem functioning depends on the functional distance among species within the community. There is increasing evidence that the biomass ratio hypothesis holds in the short term (reviewed in Garnier and Navas 2012, Lavorel 2013), but the relative importance of dominance vs. niche complementarity to explain ecosystem functioning remains an open question.

Although there are clearly multiple controls on the amount of biomass produced at a local scale, only few studies have explored more than one or two factors simultaneously (see Díaz et al. 2007a, Schumacher and Roscher 2009, Bernhardt-Romermann et al. 2011). The main objective of this study was, therefore, to assess the impacts of abiotic and biotic factors on biomass produced using the conceptual framework proposed by Díaz et al. (2007a) as a background. This was done in a Mediterranean rangeland of Southern France, where climate exerts strong controls on plant growth at different times of the year (Mitrakos 1980). Two management regimes were imposed since 1978 to the rangeland studied: The first one consisted of sheep grazing only, while the second one consisted of a combination of sheep grazing and fertilization. We used a diachronic approach spanning a 25-year period to compare the biomass produced and the functional structure of the communities in the two management regimes, and addressed the following questions: (1) What are the main climatic factors controlling rangeland standing biomass in the highly seasonal climate of Mediterranean Southern France? (2) What are the relative roles of climatic variables and components of community functional structure on rangeland standing biomass in the two management regimes?

\section{Methods}

\section{Study area}

The studied rangelands are located at the La Fage French National Institute for Agricultural Research (INRA) experimental station $\left(43^{\circ} 55^{\prime} \mathrm{N}, 3^{\circ} 05^{\prime} \mathrm{E}, 800 \mathrm{~m}\right.$ above sea level) on the western edge of the Larzac Causse, a limestone plateau in Southern France. Climate is subhumid Mediterranean type, with cold and wet winters alternating with warm and dry summers. The mean annual temperature is $9.5^{\circ} \mathrm{C}$, and precipitation ranges from 680 to $1790 \mathrm{~mm} / \mathrm{yr}$, most of which falls in spring and autumn (records over the period 1976-2005). The experimental station covers a surface area of 300 ha, 280 of which are rangelands. The vegetation of these rangelands is mostly herbaceous with scattered shrubs such as Buxus sempervirens or Juniperus communis (Bernard 1996).

\section{Vegetation characteristics}

In the mid-1970s, the 280 ha of rangelands were subdivided into 15 paddocks; six of these, which were contiguous, were used in the present study (the surface area of these six paddocks was $12.8 \pm 3.3$ ha [mean \pm $\mathrm{SE]}$ ). Two management regimes, which have remained unchanged since 1978, were imposed on this subset of paddocks (Molénat et al. 2005). The first one (grazed, unfertilized [hereafter $\mathrm{GF}$ - treatment]), consisting of a moderate grazing regime by sheep, traditional in the area, was applied to three of the paddocks. The second one (grazed, fertilized [hereafter GF+ treatment]) included a fertilization treatment with increased grazing pressure in spring. In this treatment, which was applied to the three other paddocks, mineral nitrogen $(65 \mathrm{~kg} / \mathrm{ha}$ each year) and phosphorus (40 kg/ha every three years) have been added since 1978 .

Botanical records were conducted since 1980 by the same botanist (D. Hubert) on transects randomly spread over the paddocks allocated to the two management regimes, using the point contact method (Daget and Poissonet 1971). In the GF- treatment, species composition was assessed on 11 permanent transects; each transect was $10 \mathrm{~m}$ long, and all species in contact with a vertical pin placed every $10 \mathrm{~cm}$ were recorded (100 pin points per transect) in 1980, 1986, 1995, 1999, and 2004. In the GF+ treatment, species composition was assessed yearly using 15 permanent transects; each transect was 5 $\mathrm{m}$ long, and all species in contact with a vertical pin placed every $10 \mathrm{~cm}$ were recorded (50 pin points per transect).

Aboveground biomass was collected three times a year at the end of May, July, and October, in 8 (GFtreatment) and $15(\mathrm{GF}+$ treatment) exclosure cages (1 $\mathrm{m}^{2}$ each), respectively. The collected material was then dried and weighed. Exclosure cages were located within $10 \mathrm{~m}$ of the transects used for botanical records, and were moved a few meters away after the October harvest. Aboveground biomass was measured every year since 1990 in the GF- treatment and since 1980 in the GF+ treatment.

\section{Environmental variables}

Minimum and maximum temperatures, as well as rainfall, were recorded daily at the study site. Daily soil water content of the $0-30 \mathrm{~cm}$ soil layer was estimated using a bucket-type model based on rainfall, potential evapotranspiration, and field capacity (see Boulant et al. 2008 for model description). The validity of this model 
was tested with field measurements of soil water content recorded by five DIVINER 2000-type sensors (Sentek Technologies, Stepney, Australia). Model outputs and field measurements were found to be in close association (see Appendix A). The simulated data were used to calculate relative soil water content as $\mathrm{RSWC}=\mathrm{SWC} /$ $\mathrm{SWC}_{\mathrm{FC}}$, where $\mathrm{SWC}$ is the daily soil water content, and $\mathrm{SWC}_{\mathrm{FC}}$ is the soil water content at the field capacity (Reichstein et al. 2003).

Temperature was used as a co-variable in regression models explaining differences in standing biomass. Mean daily minimum or maximum temperatures were used depending on the season, in relation to our hypotheses about temperature controls. In the study area, we expected (1) low temperatures to limit the amount of biomass produced during winter and control the start of the growing season in spring, (2) high temperatures to limit vegetation growth during summer, and (3) a double control in autumn depending on high temperatures in August and low temperatures in September and October. Periods and variables used in the calculations are given in Appendix B.

\section{Plant traits and functional structure of communities}

Six traits were measured in spring 2006 and 2007 on 78 species (55 and 48 in the GF- and GF+ treatments, respectively [ 25 being measured in both treatments]: see list in Appendix C) during the period of maximum growth of the vegetation, following standardized protocols (Cornelissen et al. 2003). Specific leaf area (SLA; the ratio of leaf area to leaf dry mass; number of replicates $n$ $=10$ ), leaf nitrogen concentration ( $\mathrm{LNC} ; n=4)$, and leaf phosphorus concentration (LPC; $n=4$ ) are traits involved in the leaf economics spectrum (Wright et al. 2004), while leaf dry matter content (LDMC; the ratio of leaf dry mass to leaf water saturated fresh mass; $n=$ 10) reflects leaf tissue density and has been shown to be highly sensitive to nutrient gradients (Hodgson et al. 2011). Reproductive plant height (Hrep; $n=30$ ) and onset of flowering (OFL; assessed by weekly censuses in each paddock over the growing season) were also measured as an overall marker of plant stature (discussed in Garnier and Navas 2012) and phenology, respectively.

Functional community structure was assessed by calculating community-weighted means (CWM; Garnier et al. 2004) and community-weighted variances (CWV; Sonnier et al. 2010) as follows:

$$
\begin{aligned}
\mathrm{CWM}_{j k} & =\sum_{i=1}^{s} p_{i k} \times t_{i j} \\
\mathrm{CWV}_{j k} & =\sum_{i=1}^{s} p_{i k} \times\left(t_{i j}\right)^{2}-\left(\mathrm{CWM}_{j k}\right)^{2}
\end{aligned}
$$

where $t_{i j}$ is the value of trait $j$ for species $i$, and $p_{i k}$ is the relative abundance of species $i$ in community $k$. CWM represents the average trait value for a unit of biomass within a community, while CWV quantifies the dispersion of trait values around the mean and can be considered as an index of functional divergence within communities (Sonnier et al. 2010). These two metrics were used (1) to describe changes in the functional structure of communities over time, and (2) to assess dominance vs. functional complementarity effects on community standing biomass: Positive associations between CWM (and, respectively, CWV) and community biomass were considered as evidence in favor of the dominance (and, respectively, complementarity) hypothesis.

The temporal trends in functional community structure were reconstructed using the vegetation relevés available through time (see section Vegetation characteristics) and the plant traits measured in 2006 and 2007, assuming that possible changes in trait values over time in response to nutrient addition had marginal effects on CWM and CWV. This assumption was tested as follows: (1) We selected transects in the GF+ treatment, for which the percent cover of species for which we had trait data measured both in the GF- and the GF+treatments was higher than $70 \%$. This was the case for 127 transects $\times$ year (i.e., roughly five transects per year, on average, over the 25-year period of study); (2) for each of these transects, we then calculated CWM and CWV using the trait values of the species measured either in the GF- or in the GF+ treatment (see Appendix C for the list of 25 species measured in both treatments). Appendix D shows tight relationships between CWM of Axis 1 of a principal component analysis (PCA) involving all six traits measured (see next section) and CWV of leaf dry matter content and reproductive height (see next section), calculated with trait data from the two treatments. We therefore considered that reconstructing the functional trajectory of communities using trait data measured at the end of the period was acceptable.

\section{Data analysis}

We used Student $t$ tests to compare the average biomass produced between treatments for each season (with Bonferroni correction of statistical significance to limit the multiple testing bias). Relationships between standing biomass and both abiotic (relative soil water content and temperature) and biotic factors (biomass produced in the previous year, CWM, and CWV; listed in Table 1) were investigated using simple and multiple regressions. Colinearity between variables was tested with the variance inflation factor (VIF; Davis et al. 1986), and only variables with a VIF $<5$ were considered (Kutner et al. 2004). Time series data can present autocorrelation that could lead to erroneous estimation of models parameters. The error-covariance structure was investigated by estimates of the autocovariance and autocorrelation function (ACF) and the residuals of each model were tested with the Ljung-Box test (Ljung and Box 1978). As there was no significant autocorrelation in our data set (see Appendix E), we 
TABLE 1. Abbreviations of variables used in the multiple regression models.

\begin{tabular}{|c|c|}
\hline Variable & Description \\
\hline Tmin & average of the daily minimum temperature \\
\hline & daily $n$ \\
\hline RSWC & average of the daily relative soil water content \\
\hline N1 & biomass of the year $n-1$ \\
\hline Rich & speci \\
\hline Axis & $\begin{array}{l}\text { axis } 1 \text { of the PCA on community-weighted } \\
\text { mean (CWM) of the six functional traits }\end{array}$ \\
\hline Axis2 & $\begin{array}{l}\text { axis } 2 \text { of the PCA on CWM of the six } \\
\text { functional traits }\end{array}$ \\
\hline $\mathrm{CWV}_{-}$ & $\begin{array}{l}\text { community-weighted variance (CWV) of leaf } \\
\text { dry matter content (LDMC) }\end{array}$ \\
\hline CWV_Hep & CWV of the reproductive plant height (Hrep) \\
\hline
\end{tabular}

conducted further analyses without using specific time series procedure.

We used a stepwise approach to select explicative abiotic and biotic factors sequentially and determine the best model (based on the Akaike information criterion [AIC]). For each of the three annual harvests, four models were compared, including: (1) only abiotic factors, (2) only functional factors, (3) all factors, and (4) factors selected by the stepwise procedure. To verify if the model selected by the stepwise procedure was sufficiently superior to reject the three others, we calculated the AIC weights, which were based on AIC scores of all models in a candidate set (Appendix F; Burnham and Anderson 2002). The values of the regression coefficients of the best model were used to compare the contribution of each variable (abiotic and biotic) to the biomass produced at each season ("strength of effects"). The best model was chosen using the $\mathrm{AIC}_{\mathrm{c}}$ criterion, an $\mathrm{AIC}$ with a greater penalty for extra parameter, as recommended by Burnham and Anderson (2002) in the case of small sample sizes.

A PCA of the CWM was conducted to depict the functional changes in communities over time. This was first performed on the combined data from the two treatments (cf. Appendix G). As there were no major changes in the species composition and functional characteristics of the GF- treatment over time, we reran the same analysis for the GF+ data only (see Appendix $\mathrm{H}$ ), and we used the first axis of this second PCA in further analyses. We did not use the same procedure for $\mathrm{CWV}$ because the interpretation of the axes of a PCA on CWV values was found to be obscure. Instead, to assess the functional divergence within communities, we used the CWV for two traits with a high contribution to the first two axes of the PCA on $\mathrm{CWM}$ values. Although not the trait with the highest contribution, LDMC was chosen to capture Axis 1 because: (1) it still contributed strongly ( 0.83 vs. 0.94 for SLA, the trait with the highest contribution; Appendix G), and (2) CWV for LDMC was less affected by changes in trait values in response to nutrient addition (see previous section and Appendix D) than CWV for
SLA (comparison not shown). Hrep was chosen to capture Axis 2 since (1) it has the highest contribution to this axis (Appendix G), and (2) changes in trait values in response to nutrient addition were found to have acceptable impacts on CWV (see previous section and Appendix D).

All statistical analyses were performed within the $R$ environment using the package ade4 (Dray and Dufour 2007, R Development Core Team 2011).

\section{Results}

\section{Climatic variation over time}

Mean annual temperature increased by $2^{\circ} \mathrm{C}$ over the 25-year study period, and only one year since 1992 was below the mean; there was no significant trend in rainfall (Appendix I). Interannual variations of rainfall were higher $(\mathrm{CV}=24.5 \%)$ than those of temperature $(\mathrm{CV}=$ $10 \%)$ and soil water content $(\mathrm{CV}=5.5 \%)$. Maximum temperature deviation was $2.3^{\circ} \mathrm{C}$ and negative (in 1985), while maximum rainfall deviation was $699 \mathrm{~mm}$ and positive (in 1996).

\section{Changes in biomass over time}

Averaged over the whole period of study, the cumulated annual standing biomass was $157 \pm 22 \mathrm{~g} /$ $\mathrm{m}^{2}$ in the GF- treatment (1990-2004 period; shown are means $\pm \mathrm{SE}$ ) and $524 \pm 41 \mathrm{~g} / \mathrm{m}^{2}$ in the GF+ treatment (1980-2004 period; Fig. 1a). In the GF+ treatment, a two-way ANOVA (exclosure cage $\times$ period) showed that the mean annual biomass produced during the 19801991 period was significantly lower than that produced over the 1992-2004 period $\left(403 \pm 99 \mathrm{~g} / \mathrm{m}^{2}\right.$ vs. $636 \mathrm{~g} / \mathrm{m}^{2}$; Student's $t$ test, $F=320, P<0.001)$. Additional analyses were therefore conducted separately for these two phases and presented in Appendices $\mathbf{J}$ and $\mathrm{K}$.

Biomass produced in May represented $\sim 60 \%$ of the cumulated annual standing biomass in both plant communities (Fig. 1; Appendix K). The increase in standing biomass in response to fertilization differed between seasons (Fig. 1). In May and October, it was four $\left(96 \pm 18 \mathrm{~g} / \mathrm{m}^{2}\right.$ in $\mathrm{GF}-$ and $445 \pm 22 \mathrm{~g} / \mathrm{m}^{2}$ in GF+, $P<0.001$ [Bonferonni $0.05 / 3=0.017$ ]; Fig. 1 b) and five $\left(19.5 \pm 5 \mathrm{~g} / \mathrm{m}^{2}\right.$ in $\mathrm{GF}-$ and $100 \pm 8 \mathrm{~g} / \mathrm{m}^{2}$ in GF,$+ P<$ 0.001 [Bonferonni $0.05 / 3=0.017$ ]; Fig. 1d) times higher, respectively, while it was only two times higher in July $\left(41 \pm 8 \mathrm{~g} / \mathrm{m}^{2}\right.$ in GF- and $70 \pm 7 \mathrm{~g} / \mathrm{m}^{2}$ in GF+, $P<0.01$ [Bonferonni 0.05/3 $=0.017$ ]; Fig. 1c).

Interannual variations were high in both treatments, with variations up to twofold between years (Fig. 1).

\section{Effects of climate and previous year biomass on standing biomass}

In both treatments, standing biomass in May was positively related to the minimum temperatures of the two months preceding harvest and to the biomass produced the previous year (Fig. 2, Table 2; see Appendix J for separate analyses of the 1980-1991 

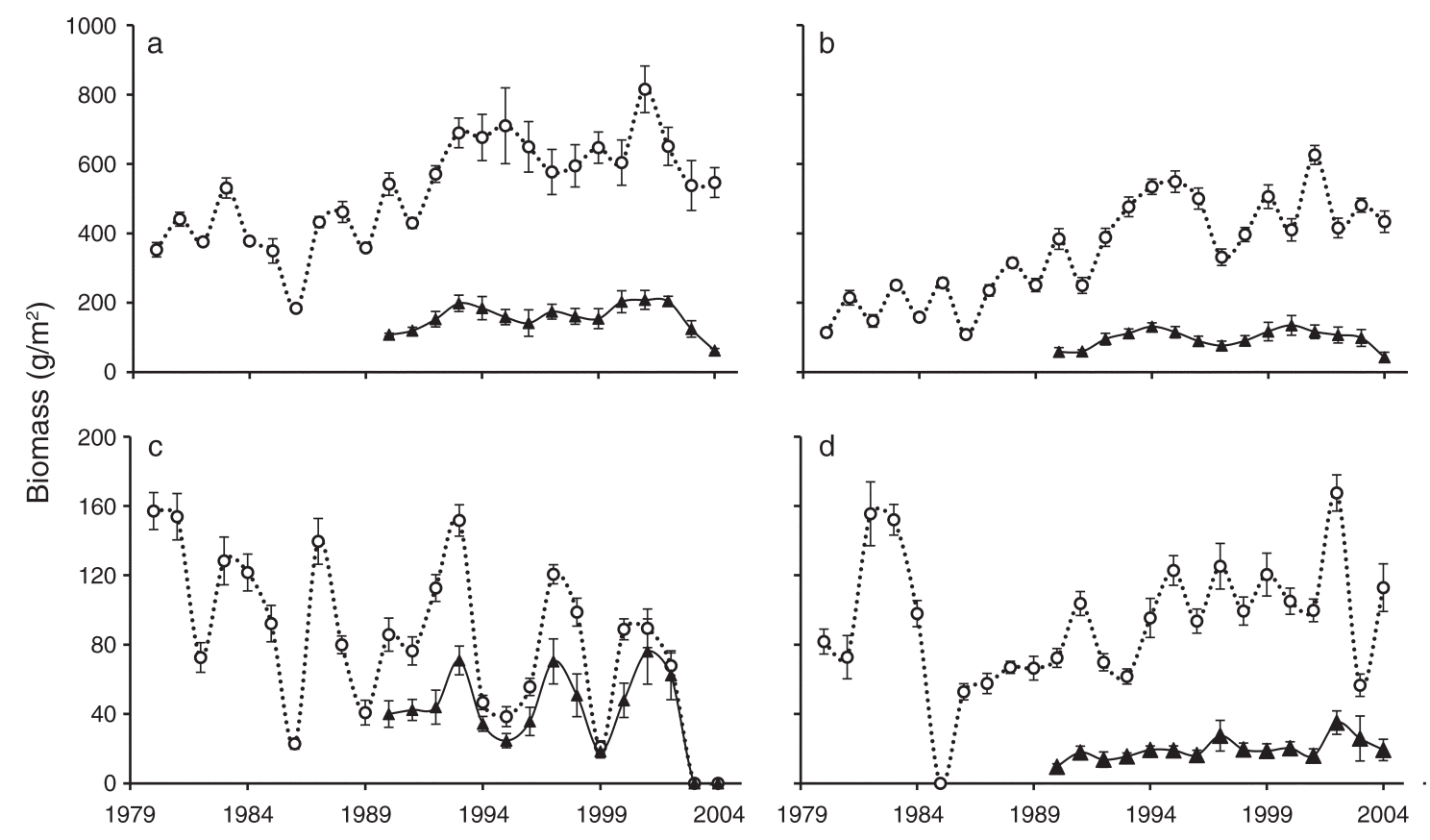

FIG. 1. Standing biomass in grazed, unfertilized treatments (GF-; solid triangle, solid lines) and in grazed, fertilized treatments (GF+; open circles, dotted lines) from 1980 to 2004 for GF+, and from 1990 to 2004 for GF-: (a) cumulated annual biomass, (b) standing biomass in May (peak standing biomass), (c) standing biomass in July, (d) standing biomass in October. Note the differences in scale between $(a, b)$ and $(c, d)$.

and 1992-2004 periods). There was no significant effect of the other climatic variables.

In July, there was a negative effect of maximum temperatures of the two months preceding the harvest and a positive effect of relative soil water content (Fig. 2, Table 2; Appendix J). Qualitatively comparable relationships were found in the case of the biomass produced in October, but only in the GF+ treatment (Fig. 2, Table 2; Appendix J). We did not find any significant relationships in the GF- treatment for this autumn harvest (Appendix J).

\section{Species and functional shifts in communities}

Species composition remained very stable in the GFcommunities over the study period, while there were substantial changes in the GF+ treatment (Appendix L). Species richness did not change significantly over time, except in 2004, following the very dry 2003 (not shown). The first axis of the principal component analysis conducted on CWMs for the two treatments differentiates communities on the basis of specific leaf area (SLA) and leaf nitrogen and phosphorus concentrations (LPC and $\mathrm{LNC}$ ) on the negative end, and of leaf dry matter content (LDMC) and onset of flowering (OFL) on the positive end (Appendix G). The second axis was mainly determined by reproductive plant height (Hrep). Based on this PCA, the functional composition of the GFcommunity remained very stable over the study period, while a clear directional change took place in the GF+ communities since the onset of fertilization (Fig. 3a;
Appendix H: Fig. H1 [see the legends to these two figures for statistics for these trends]). The functional change in the GF+ community corresponded to a negative shift along the first axis of the PCA: A change from a community dominated by species with high LDMC values to a community characterized by species with high SLA, LPC, and LNC.

In the GF- communities, there was no significant temporal change in terms of variance associated to traits, while substantial changes occurred in the GF+ communities (Fig. 3b, c; see figure legend for statistics): CWV_LDMC fluctuated during the first nine years and stabilized after 1989; the trend for CWV_Hrep was more consistent, with a continuous decrease until 1993 when it stabilized, with some oscillations between years from 1994 on.

\section{Effects of changes in functional composition on standing biomass}

In $\mathrm{GF}+$, peak standing biomass in May was correlated to different components of functional community structure (Fig. 4). It was negatively related: (1) to Axis 1 of the PCA (more productive communities tended to have high CWM_SLA, LNC, and LPC values, low LDMC and OFL values; cf. Appendix G), and (2) to CWV_LDMC and CWV_Hrep (more productive communities tended to have low weighted variance of both traits). In July, there was a positive relationship with Axis 1 of the PCA on trait CWMs. None of the functional variables considered had a significant effect 


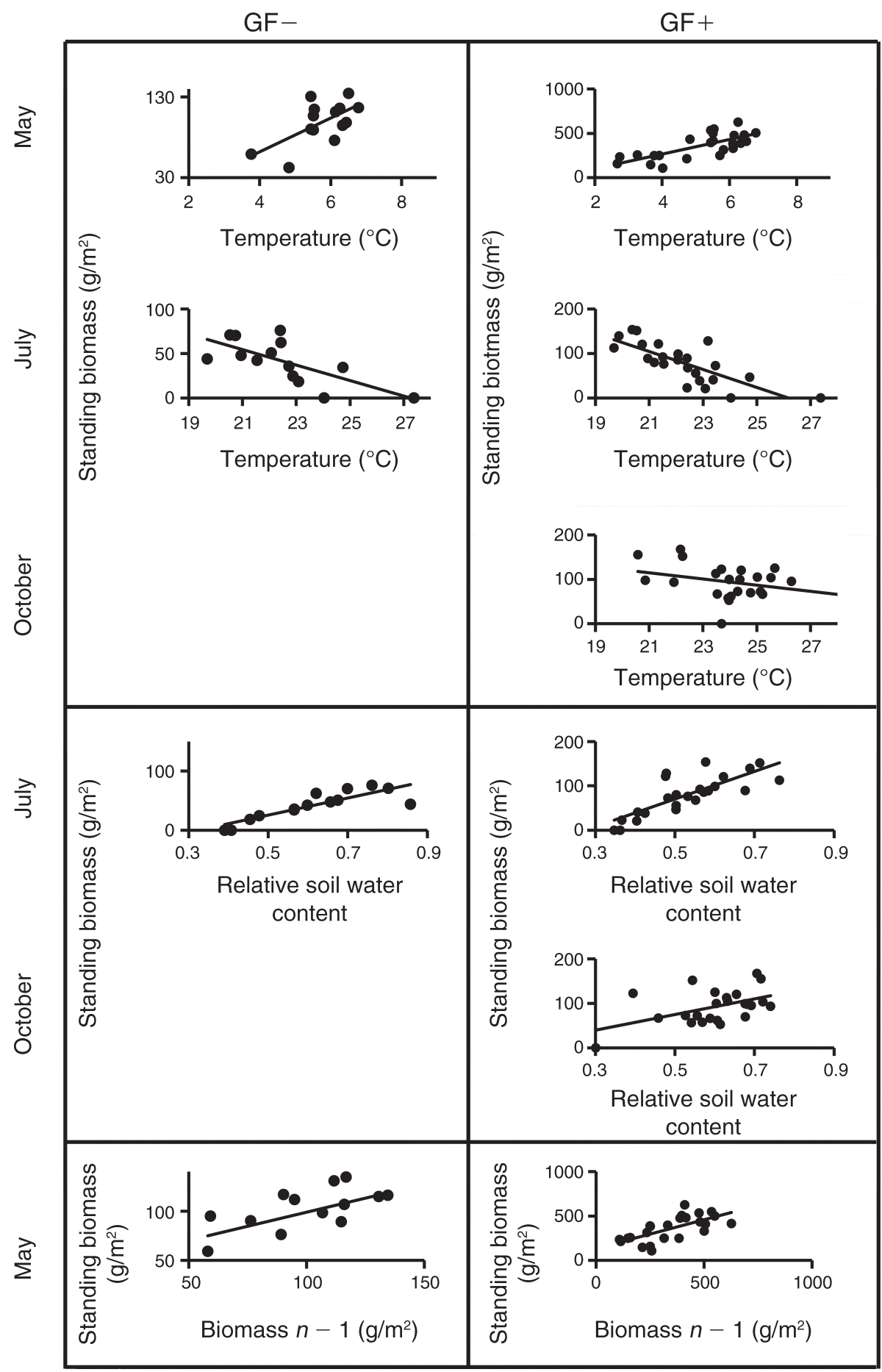

FIG. 2. Relationships between abiotic variables and standing biomass for GF- (left) and GF+ (right) communities. Biomass $n$ -1 is the biomass produced during the preceding year $(n-1)$. Relationships are presented only for those parameters that were found to be significant. See Appendix B for details of variables used and periods of calculation for each harvest. Statistics for the choice of variables are given in Table 2 (GF+ treatment over the 1980-2004 period) and Appendix J (GF- treatment and GF+ treatment for the 1980-1990 and the 1990-2004 phases analyzed separately). 
TABLE 2. Variables retained in the multiple regression models with standing biomass as a dependent variable for each harvest in the grazed, fertilized community $(\mathrm{GF}+)$.

\begin{tabular}{lccc}
\hline \hline \multicolumn{1}{c}{ Variable } & May harvest & July harvest & October harvest \\
\hline RSWC & 1.70 & $3.36^{* *}$ & $3.32^{* *}$ \\
Tmin & $2.39^{*}$ & $\ldots$ & $4.73^{* * *}$ \\
Tmax & $\ldots$ & -1.06 & $-4.43^{* * *}$ \\
N1 & $\ldots$ & $\ldots$ & $2.66^{*}$ \\
Axis1 & -0.96 & $2.10^{*}$ & $\ldots$ \\
Axis2 & $\ldots$ & $\ldots$ & $-2.98^{*}$ \\
CWV_LDMC & $\ldots$ & 0.50 & $2.37^{*}$ \\
CWV_Hrep & $-2.17^{*}$ & 0.19 & $\ldots$ \\
Total $\left(R^{2}\right)$ & $0.78^{* * *}$ & $0.80^{* * *}$ & $0.75^{* * *}$ \\
\hline
\end{tabular}

Notes: Values are the regression coefficients of the different models. The last row gives the coefficient of determination $\left(R^{2}\right)$ for each model with its significance level. See Table 1 for abbreviations. Ellipses show where a variable was not retained in the model.

* $P<0.05 ; * * P<0.01 ; * * * P<0.001$.

on the biomass produced in October when considered alone.

\section{Climatic vs. biotic controls in the fertilized community}

As there were no significant changes in any aspect of community structure in the GF- treatment (Fig. 3), we then tested the relative contributions of abiotic and biotic factors on standing biomass only in the GF+ community. The procedure of model selection indicates that standing biomass was always better explained by a combination of abiotic and biotic factors than by one category of factor alone (Appendix F). In May and July, multiple regressions indicate that standing biomass was simultaneously controlled by primary variables (with significant coefficients) and also by secondary variables (not significant, but selected in the stepwise procedure). In May, peak standing biomass was primarily dependent on minimum temperature during spring and on the CWV_Hrep (variables with significant coefficients; Table 2). Two other factors, the relative soil water content and CWM Axis 1, were also retained in the model (Table 2). In July, the main factors retained were RSWC and Axis 1 of the PCA on CWMs (positive). CWV_LDMC, CWV_Hrep, and maximum temperatures in the period preceding the harvest were also associated to standing biomass, but to a lower extent (Table 2). Finally, a combination of three climatic and three biotic variables were retained in the model corresponding to the biomass produced in October.

With $75-80 \%$ of the variance explained, the models selected explained a large proportion of the interannual variations of standing biomass (Table 2).

\section{Discussion}

Over the 1991-2004 period, the mean annual biomass produced was $\sim 157 \mathrm{~g} / \mathrm{m}^{2}$ in the grazed unfertilized community, which is comparable to the values found in herbaceous Mediterranean old fields located $100 \mathrm{~km}$ southeast of the La Fage experimental station (Garnier et al. 2004). This is well below the average value reported by Saugier et al. (2001) for temperate grasslands $\left(250 \mathrm{~g} / \mathrm{m}^{2}\right)$, and corresponds to the low end of values found for grasslands along a rainfall gradient in the United States (Sala et al. 1988). The biomass produced in the grazed fertilized treatment was approximately three times higher, demonstrating that (1) these rangelands are nutrient limited, as other Mediterranean ecosystems (e.g., di Castri 1981, Margaris et al. 1984), and (2) the effects of increased grazing pressure, which induces a decrease in biomass production in most systems (Milchunas and Lauenroth 1993, Oesterheld et al. 1999), are more than offset by those resulting from nutrient addition. The results of this long-term experi-
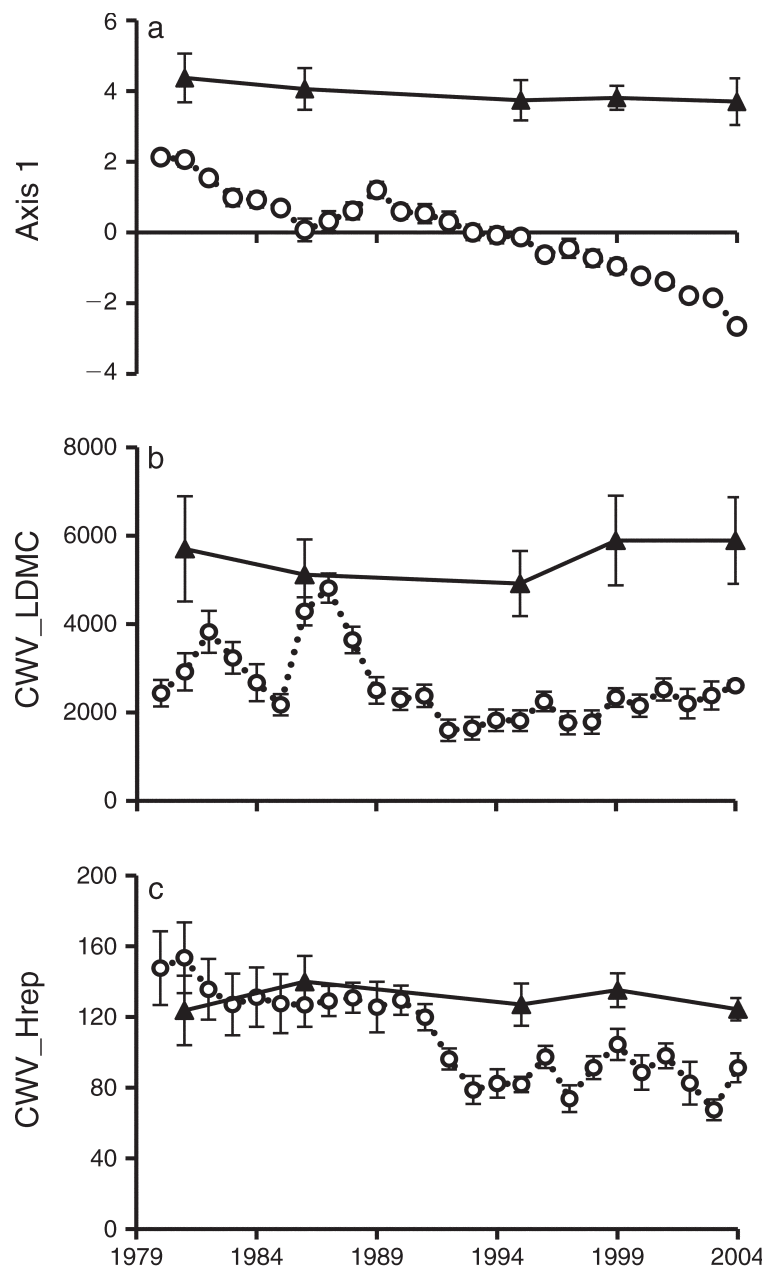

FIG. 3. Temporal changes in (a) Axis 1 of the principal component analysis (PCA) conducted on the communityweighted mean of traits (cf. Appendix H), (b) communityweighted variance (CWV) of leaf dry matter content (LDMC), and (c) reproductive plant height (Hrep) since 1980 in GF(solid triangles, solid lines) and GF+ (open circles, dotted lines) communities. Pearson correlations between time and either Axis 1 of the PCA, CWV_LDMC, or CWV_Hrep were not significant in GF- (for [a], $r=-0.43, P>0.05$; for [b], $r=0.33$, $P>0.05$; for [c] $, r=-0.11, P>0.05)$, while they were in GF+ (for [a], $r=-0.95, P<0.001$; for [b], $r=-0.47, P<0.05$; for [c], $r=-0.86, P<0.001)$. 


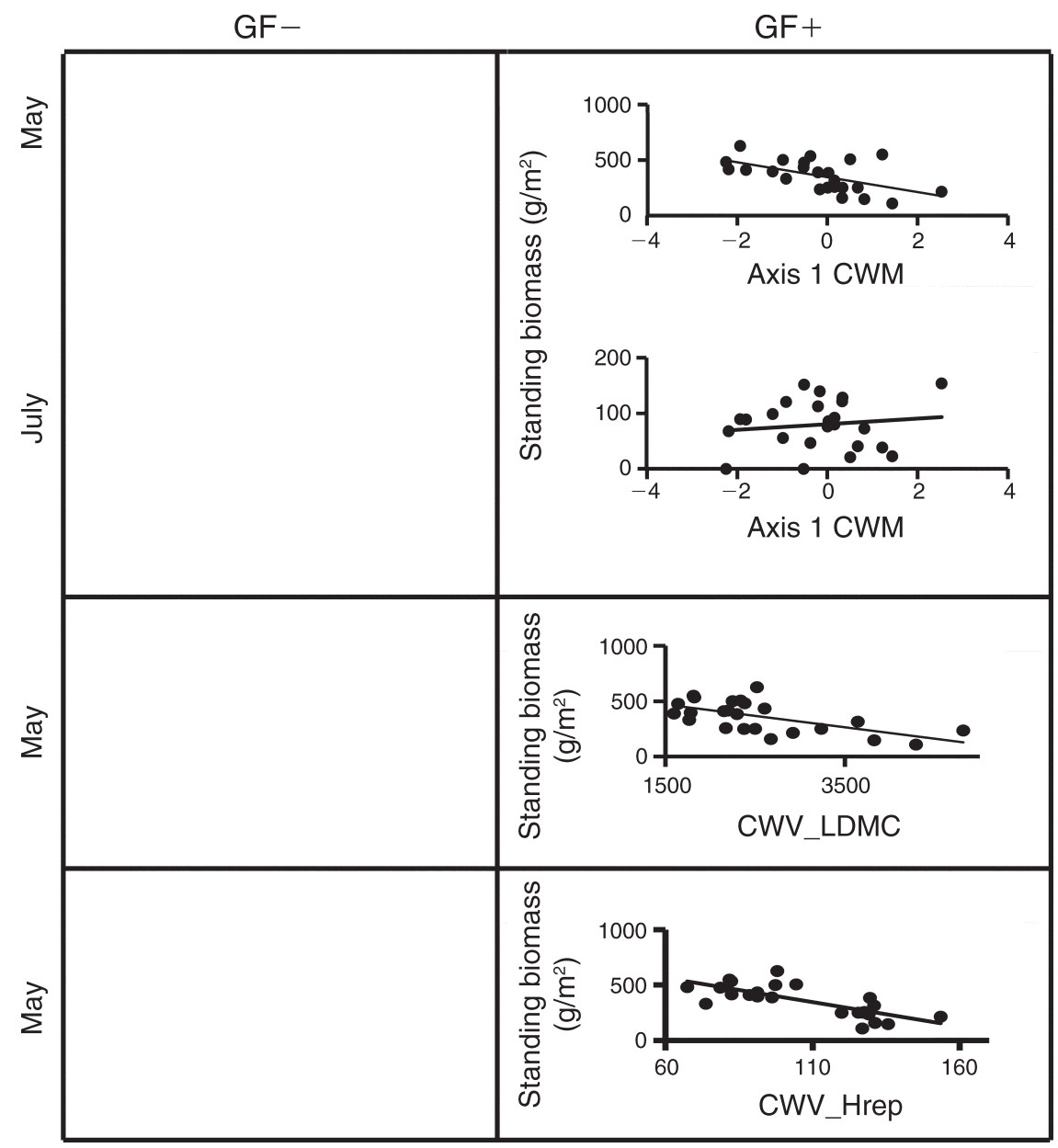

FIG. 4. Relationships between different components of community structure and standing biomass in May and July for GF(left) and GF+ (right) communities. Relationships are presented only for those parameters that were found to be significant (none were significant for GF-). See Table 1 for definitions of variables used.

ment show that climate, resource availability, and the functional structure of communities have significant effects on the biomass produced in these rangelands. In the next section, we discuss how the changes in management regime affect the plant community structure before discussing the combined effects of the different factors in the subsequent section.

\section{Community responses to changes in the management regime}

In the GF+ treatment, the perennial species (e.g., Festuca christiani-bernardii and Carex humilis), which were initially codominant with Bromus erectus, were gradually replaced by annual species such as Vulpia myuros and Bromus hordeaceus, while in the GFtreatment, these same three perennials remained the most abundant species throughout the study period (Appendix L). Species changes in GF+ are in agreement with previous studies reporting a replacement of perennial by annual species under increased grazing pressure (reviewed in Díaz et al. 2007b). This shift in species composition occurred without significant changes in species richness, showing that the higher grazing intensity could be supported at this higher resource level without altering species number (Cingolani et al. 2005).

In GF+, changes in species composition were associated with changes in the community-weighted mean of functional traits (CWM), and there was no sign that these shifts were completed 25 years after the onset of the modified regime. Species with high rates of resource acquisition were progressively filtered in, leading to communities with high CWM_SLA, LNC and LPC, and low CWM_LDMC, with an overall earlier flowering phenology. This association of traits reflects a combined response to increased nutrient availability and grazing pressure (Lavorel et al. 2007, Garnier and Navas 2011). By contrast, there was no significant effect on CWM_Hrep. In addition to these changes in CWM values over time, community-weighted variances of traits (CWV) were also modified by the change in management regime. The oscillating pattern of CWV_LDMC is not straightforward to interpret, but 
the significant negative trend in CWV_Hrep shows that fertilization and increased grazing pressure led to a homogenization of the communities with respect to reproductive plant height. Such a decrease in plant height variance with higher nutrient availability has also been found in mountain grasslands by Lavorel et al. (2011), but further studies are warranted to test whether this trend is general.

In $\mathrm{GF}-$, where the management regime remained unaltered as compared to the 10 years preceding the study period, species composition and community functional structure remained remarkably stable throughout the 1980-2004 period. As a consequence, the functional distance between the two types of communities was highest at the end of the study period, both in terms of weighted means and variances.

\section{Controls on rangeland biomass differ among seasons}

A prominent result of our study is that both abiotic and biotic factors controlling the amount of biomass produced were found to change according to the period of the year (Figs. 2 and 4, Table 2). This has recently been stressed for climate by La Pierre et al. (2011) in a mesic grassland, in which separating variables into specific periods of the growing season was more powerful than using mean annual rainfall or temperature to detect the climatic signals on production (see also Fay et al. 2003, Nippert et al. 2006, Muldavin et al. 2008, Craine et al. 2012). Control on interannual variations of biomass production by climate has been found in semiarid and arid ecosystems (Briggs and Knapp 1995, Veron et al. 2002), but this was not the case in several studies conducted in temperate systems (e.g., Jobbagy and Sala 2000, Lauenroth and Burke 2008, Gibson 2009). Whether this is the consequence of using climatic variables that are too coarse remains to be investigated. In addition, running a soil water balance model such as that used here certainly provides us with a better assessment of water limitation than annual rainfall data.

To our knowledge, our study is the first to show that the same applies for biotic factors, with opposite effects of the two components of functional community structure in May and July in the GF+ treatment (Fig. 4, Table 2), where fertilization coupled with the increased grazing intensity during spring induced an overall change in species composition and traits. The lack of any variation in community functional structure in GF- implies that only the effects of climate on standing biomass could be directly assessed in this treatment.

Spring standing biomass.-In both treatments, the biomass produced in May (roughly 60\% of the cumulated annual biomass produced) was dependent on low temperatures during the beginning of the growing season after winter. In GF+, the strength of this effect is highest, but the combined model also shows a strong negative effect of CWV_Hrep. Higher production associated with lower functional diversity within communities has been found in several studies (Mokany et al. 2008, Conti and Díaz 2013, Grigulis et al. 2013), but not in others (Klumpp and Soussana 2009, Schumacher and Roscher 2009, Mouillot et al. 2011), which tend to show that a higher functional divergence is not a prerequisite for a higher production. In GF+, higher peak standing biomass was also, but less strongly, associated with higher soil water content and with the shift in CWM_Axis1. Higher standing biomass with higher CWM_SLA and/or CWN_LNC and lower CWM_LDMC (two of the traits that contribute to Axis 1 of the PCA conducted in the present study) have also been found in mountain grasslands (Lavorel et al. 2011, Grigulis et al. 2013), while Garnier et al. (2004) found weak negative relationships with CWM_SLA and CWM_LDMC in Mediterranean old fields. Mokany et al. (2008) and Schumacher and Roscher (2009) did not find any significant relationships between standing biomass and CWM_SLA (both studies) or CWM_LDMC (Mokany et al. 2008) in Australian and Central European grasslands, respectively. We did not find any significant relationship with CWM plant height in our system (not shown), which implies that the higher standing biomass is achieved by an increase in the vertical density of biomass within the canopy. This contrasts with studies conducted in mountain grasslands of the French Alps (Lavorel et al. 2011, Grigulis at al. 2013) and in the Chaco forest in Argentina (Conti and Díaz 2013) where higher biomass is produced in taller communities.

Summer and autumn standing biomass.-The biomass produced in July was positively related to soil water content and negatively related to temperature in both treatments. In GF+, this was the strongest effect, followed by that of CWM_Axis1, but reversed as compared to that found in May. This might be related to the shift in species composition towards annuals which tend to complete their life cycle, and hence produce biomass, earlier in the spring (lower CWM_OFL in GF+, corresponding to earlier flowering), and die. By contrast to what was observed in May, higher functional divergence is associated with higher standing biomass in July, but the strength of these effects are relatively small.

In October, we did not find any significant relationship between climate and standing biomass in GF-. In $\mathrm{GF}+$, the combined model showed strong effects of soil water content and temperature, and yet different effects of functional community structure, weaker than those of climate: The amount of biomass produced was associated with tall plants with more divergent communities, as in summer.

\section{Environmental and biotic controls on standing biomass: a synthesis}

Our results in the GF+ treatment can be used to assess the hypotheses put forward by Díaz et al. (2007a), who designed a framework aiming at successively identifying 
the effects of abiotic, factors, trait CWM and variance (CWV in our case), and possible residual species-specific effects. Different environmental effects (temperature and water availability) appear to be the primary factors controlling the amount of biomass produced in all seasons in our system, but the effects of the two components of community functional structure are not consistent among seasons: As assumed by Díaz et al. (2007a), the effects of CWM are positive in spring, but they are negative in summer and shift to a different axis in autumn, while the effects of CWV are negative (assumed positive) and actually positive in summer and autumn. Overall, the biotic effects detected are in support of the dominance hypothesis for the period of maximum production in spring, while functional divergence among species appears to increase the biomass produced during the two periods of lower production in summer and autumn, which tends to support the complementarity hypothesis.

\section{Conclusions}

The amount of biomass produced in the Mediterranean rangelands studied was found to be highly predictable (between $75 \%$ and $80 \%$ of variance explained) from a combination of abiotic and biotic variables, but these controls were found to change according to the season. Climatic variables were always found to have strong impacts in both treatments, but the changes in management regime induced a progressive shift in the functional structure of plant communities, leading to additional variables almost as strongly associated with standing biomass. The components of the functional structure associated with the amount of biomass produced differed among season: A high peak standing biomass in spring (60\% of the annual biomass) was achieved in communities dominated by few fastgrowing species that are functionally close, in clear support of dominance hypothesis (Grime 1998), rather than of the niche complementarity hypothesis (Petchey and Gaston 2006). The standing biomass in summer and autumn ( $40 \%$ of the annual total) were associated with higher functional divergence in the communities as well, thereby modulating this conclusion.

\section{ACKNOWLEDGMENTS}

This study was partially funded by the French national INRA-EcoGer project DivHerbe (Structure, diversité et fonctionnement: des clés multi-échelles pour la gestion des prairies permanentes) coordinated by Pablo Cruz (INRA Toulouse, France). We thank the technical staff of the La Fage INRA experimental station for facilities and support to carry out the field work. We also thank Olivier Gimenez, Denis Vile, and Cyrille Violle for their useful advice at different stages of the data analyses. This is a publication from the GDR 2574 "TRAITS" (CNRS, France).

\section{Literature Cited}

Bernard, C. 1996. Flore des Causses. Bulletin de la Société Botanique du Centre-Ouest. Nouvelle série. Special issue 31: $1-784$.
Bernhardt-Romermann, M., C. Romermann, S. Sperlich, and W. Schmidt. 2011. Explaining grassland biomass: the contribution of climate, species and functional diversity depends on fertilization and mowing frequency. Journal of Applied Ecology 48:1088-1097.

Boulant, N., G. Kunstler, S. Rambal, and J. Lepart. 2008. Seed supply, drought, and grazing determine spatio-temporal patterns of recruitment for native and introduced invasive pines in grasslands. Diversity and Distributions 14:862-874.

Briggs, J. M., and A. K. Knapp. 1995. Interannual variability in primary production in tall grass prairie: climate, soilmoisture, topographic position, and fire as determinants of aboveground biomass. American Journal of Botany 82:10241030.

Burnham, K. P., and D. R. Anderson. 2002. Model selection and multimodel inference: a practical information-theoretical approach. Second edition. Springer, New York, New York, USA.

Chapin, F. S., III, P. A. Matson, and H. A. Mooney. 2002. Principles of terrestrial ecosystem ecology. Springer, New York, New York, USA.

Cingolani, A. M., M. Cabido, D. E. Gurvich, D. Renison, and S. Díaz. 2007. Filtering processes in the assembly of plant communities: Are species presence and adundance driven by the same traits? Journal of Vegetation Science 18:911-920.

Cingolani, A. M., I. Noy-Meir, and S. Diaz. 2005. Grazing effects on rangeland diversity: a synthesis of contemporary models. Ecological Applications 15:757-773.

Conti, G., and S. Díaz. 2013. Plant functional diversity and carbon storage: an empirical test in semi-arid forest ecosystems. Journal of Ecology 101:18-28.

Cornelissen, J. H. C., et al. 2003. A handbook of protocols for standardised and easy measurement of plant functional traits worldwide. Australian Journal of Botany 51:335-380.

Craine, J. M., J. B. Nippert, A. J. Elmore, A. M. Skibbe, S. L. Hutchinson, and N. A. Brunsell. 2012. Timing of climate variability and grassland productivity. Proceedings of the National Academy of Sciences USA 109:3401-3405.

Crawley, M. J., A. E. Johnston, J. Silvertown, M. Dodd, C. de Mazencourt, M. S. Heard, D. F. Henman, and G. R. Edwards. 2005. Determinants of species richness in the Park Grass Experiment. American Naturalist 165:179-192.

Daget, P., and J. Poissonet. 1971. Une méthode d'analyse phytologique des prairies. Critères d'application. Annales Agronomiques 22:5-41.

Davis, C. E., J. E. Hyde, S. I. Bangdiwala, and J. J. Nelson. 1986. An example of dependencies among variables in a conditional logistic regression. Pages $140-147$ in S. H. Moolgavkar and R. L. Prentice, editors. Modern statistical methods in chronic disease epidemiology. Wiley, New York, New York, USA.

di Castri, F. 1981. Mediterranean-type shrublands of the world. Pages 1-52 in F. Di Castri, D. W. Goodall, and R. L. Specht, editors. Mediterranean-type shrublands. Elsevier Scientific, Amsterdam, The Netherlands.

Díaz, S., S. Lavorel, F. de Bello, F. Quetier, K. Grigulis, and M. Robson. 2007a. Incorporating plant functional diversity effects in ecosystem service assessments. Proceedings of the National Academy of Sciences USA 104:20684-20689.

Díaz, S., et al. 2007b. Plant trait responses to grazing: a global synthesis. Global Change Biology 13:313-341.

Dray, S., and A. B. Dufour. 2007. The ade4 package: Implementing the duality diagram for ecologists. Journal of Statistical Software 22:1-20.

Duru, M., G. Lemaire, and P. Cruz. 1997. Grasslands. Pages 59-72 in G. Lemaire, editor. Diagnosis of the nitrogen status in crops. Springer-Verlag, Berlin, Germany.

Fay, P. A., J. D. Carlisle, A. K. Knapp, J. M. Blair, and S. L. Collins. 2003. Productivity responses to altered rainfall patterns in a C-4-dominated grassland. Oecologia 137:245251. 
Garnier, E., et al. 2004. Plant functional markers capture ecosystem properties during secondary succession. Ecology 85:2630-2637.

Garnier, E., and M.-L. Navas. 2011. Assessing the functional role of plant diversity in grasslands: a trait-based approach. Pages 138-147 in G. Lemaire, J. G. Hodgson, and A. Chabbi, editors. Grassland productivity and ecosystem. CAB International, Wallingford, UK.

Garnier, E., and M.-L. Navas. 2012. A trait-based approach to comparative functional plant ecology: concepts, methods and applications for agroecology. A review. Agronomy for Sustainable Development 32:365-399.

Gaujour, E., B. Amiaud, C. Mignolet, and S. Plantureux. 2012. Factors and processes affecting plant biodiversity in permanent grasslands. A review. Agronomy for Sustainable Development 32:133-160.

Gibson, D. J. 2009. Grasses and grassland ecology. Oxford University Press, Oxford, UK.

Gough, L., C. W. Osenberg, K. L. Gross, and S. L. Collins. 2000. Fertilization effects on species density and primary productivity in herbaceous plant communities. Oikos 89:428-439.

Grigulis, K., et al. 2013. Relative contributions of plant traits and soil microbial properties to mountain grassland ecosystem services. Journal of Ecology 101:47-57.

Grime, J. P. 1998. Benefits of plant diversity to ecosystems: immediate, filter and founder effects. Journal of Ecology 86: 902-910.

Hodgson, J. G., et al. 2011. Is leaf dry matter content a better predictor of soil fertility than specific leaf area? Annals of Botany 108:1337-1345.

Jobbagy, E. G., and O. E. Sala. 2000. Controls of grass and shrub aboveground production in the Patagonian steppe. Ecological Applications 10:541-549.

Klumpp, K., and J. F. Soussana. 2009. Using functional traits to predict grassland ecosystem change: a mathematical test of the response-and-effect trait approach. Global Change Biology 15:2921-2934.

Knapp, A. K., and M. D. Smith. 2001. Variation among biomes in temporal dynamics of aboveground primary production. Science 291:481-484.

Kutner, M. H., C. J. Nachtsheim, J. Neter, and W. Li. 2004. Applied linear regression models. McGraw-Hill Irwin, New York, New York, USA.

La Pierre, K. J., S. H. Yuan, C. C. Chang, M. L. Avolio, L. M. Hallett, T. Schreck, and M. D. Smith. 2011. Explaining temporal variation in above-ground productivity in a mesic grassland: the role of climate and flowering. Journal of Ecology 99:1250-1262.

Lauenroth, W. K., and I. C. Burke. 2008. Ecology of the shortgrass steppe: a long-term perspective. Oxford University Press, Oxford, UK.

Lauenroth, W. K., and O. E. Sala. 1992. Long-term forage production of North-American shortgrass steppe. Ecological Applications 2:397-403.

Lavorel, S. 2013. Plant functional effects on ecosystem services. Journal of Ecology 101:4-8.

Lavorel, S., et al. 2007. Plant functional types: Are we getting any closer to the Holy Grail? Terrestrial ecosystems in a changing world. Pages 149-164 in J. G. Canadell, D Pataki, and L. Pitelka, editors. Springer, Berlin, Germany.

Lavorel, S., and E. Garnier. 2002. Predicting changes in community composition and ecosystem functioning from plant traits: revisiting the Holy Grail. Functional Ecology 16: $545-556$.

Lavorel, S., K. Grigulis, P. Lamarque, M. P. Colace, D. Garden, J. Girel, G. Pellet, and R. Douzet. 2011. Using plant functional traits to understand the landscape distribution of multiple ecosystem services. Journal of Ecology 99:135-147.

LeBauer, D. S., and K. K. Treseder. 2008. Nitrogen limitation of net primary productivity in terrestrial ecosystems is globally distributed. Ecology 89:371-379.
Lemaire, G., J. G. Hodgson, and A. Chabbi, editors. 2011. Grassland productivity and ecosystem services. CAB International, Oxfordshire, UK.

Ljung, G. M., and G. E. P. Box. 1978. Measure of lack of fit in time-series models. Biometrika 65:297-303.

Margaris, N. S., S. Adamandiadou, L. Siafaca, and J. Diamantopoulos. 1984. Nitrogen and phosphorus-content in plant species of Mediterranean ecosystems in Greece. Vegetatio 55:29-35.

Milchunas, D. G., and W. K. Lauenroth. 1993. Quantitative effects of grazing on vegetation and soils over a global range of environments. Ecological Monographs 63:327-366.

Mitrakos, K. 1980. A theory for Mediterranean plant life. Acta Oecologica-Oecologia Plantarum 1:245-252.

Mokany, K., J. Ash, and S. Roxburgh. 2008. Functional identity is more important than diversity in influencing ecosystem processes in a temperate native grassland. Journal of Ecology 96:884-893.

Molénat, G., D. Foulquié, P. Autran, J. Bouix, D. Hubert, M. Jacquin, F. Bocquier, and B. Bibé. 2005. Pour un élevage ovin allaitant performant et durable sur parcours: un système expérimental sur le Causse du Larzac. INRA Productions Animales 18:323-338.

Mouillot, D., S. Villéger, M. Scherer-Lorenzen, and N. W. H. Mason. 2011. Functional structure of biological communities predicts ecosystem multifunctionality. PLoS ONE 6:e17476.

Muldavin, E. H., D. I. Moore, S. L. Collins, K. R. Wetherill, and D. C. Lightfoot. 2008. Aboveground net primary production dynamics in a northern Chihuahuan Desert ecosystem. Oecologia 155:123-132.

Nippert, J. B., A. K. Knapp, and J. M. Briggs. 2006. Intraannual rainfall variability and grassland productivity: can the past predict the future? Plant Ecology 184:65-74.

Oesterheld, M., J. Loreti, M. Semmartin, and J. M. Paruelo. 1999. Grazing, fire and climate effects on primary productivity of grasslands and savannas. Pages 287-306 in L. R. Walker, editor. Ecosystems of the world. Volume 16: Ecosystems of disturbed grounds. Elsevier, Amsterdam, The Netherlands.

Oesterheld, M., J. Loreti, M. Semmartin, and O. E. Sala. 2001. Inter-annual variation in primary production of a semi-arid grassland related to previous-year production. Journal of Vegetation Science 12:137-142.

Petchey, O. L., and K. J. Gaston. 2006. Functional diversity: back to basics and looking forward. Ecology Letters 9:741-758.

R Development Core Team 2011. R: a language and environment for statistical computing. R Foundation for Statistical Computing, Vienna, Austria.

Reichstein, M., et al. 2003. Modeling temporal and large-scale spatial variability of soil respiration from soil water availability, temperature and vegetation productivity indices. Global Biogeochemical Cycles 17:1-15.

Sala, O. E., W. J. Parton, L. A. Joyce, and W. K. Lauenroth. 1988. Primary production of the central grassland region of the United States. Ecology 69:40-45.

Saugier, B., J. Roy, and H. A. Mooney. 2001. Estimations of global terrestrial productivity: converging towards a single number? Pages 543-557 in J. Roy, B. Saugier, and H. A. Mooney, editors. Terrestrial global productivity. Academic Press, San Diego, California, USA.

Schumacher, J., and C. Roscher. 2009. Differential effects of functional traits on aboveground biomass in semi-natural grasslands. Oikos 118:1659-1668.

Sonnier, G., B. Shipley, and M. L. Navas. 2010. Quantifying relationships between traits and explicitly measured gradients of stress and disturbance in early successional plant communities. Journal of Vegetation Science 21:1014-1024.

Veron, S. R., J. M. Paruelo, O. E. Sala, and W. K. Lauenroth. 2002. Environmental controls of primary production in agricultural systems of the Argentine Pampas. Ecosystems 5:625-635.

Wright, I. J., et al. 2004. The worldwide leaf economics spectrum. Nature 428:821-827. 


\section{Supplemental Material}

\section{Appendix A}

Predicted and observed soil water content in the upper $30 \mathrm{~cm}$ from January to December in 2008, together with daily rainfall during the same period (Ecological Archives E095-061-A1).

\section{Appendix B}

Periods of the year and variables used to assess the abiotic controls on biomass production: relative soil water content and temperature (Ecological Archives E095-061-A2).

\section{Appendix C}

List of species on which traits were measured, together with their botanical family and life cycle (Ecological Archives E095-061-A3).

\section{Appendix D}

Comparison of community-weighted means for Axis 1, leaf dry matter content, and reproductive height calculated with traits value measured in the two treatments (Ecological Archives E095-061-A4).

\section{Appendix E}

Results of Ljung-Box tests to investigate the autocorrelation structure in residuals of the models used in multiple regressions (Ecological Archives E095-061-A5).

\section{Appendix F}

AIC table for the candidate multiple regression models (Ecological Archives E095-061-A6).

\section{Appendix G}

Trait ordination shown in the factorial plan 1-2 of the principal component analysis (PCA) performed on the communityweighted means matrix using data from the two treatments (Ecological Archives E095-061-A7).

\section{Appendix $\mathbf{H}$}

Trait ordination shown in the factorial plan 1-2 of the PCA performed on the community-weighted means matrix using data from the grazed/fertilized treatment and temporal changes in Axis 1 of the PCA conducted on community-weighted mean of traits since 1980 in the grazed/fertilized treatment (Ecological Archives E095-061-A8).

\section{Appendix I}

Deviation of annual values from the average for the period 1980-2004 for minimal and maximal temperatures, rainfall, and relative soil water content for the La Fage experimental station (Ecological Archives E095-061-A9).

\section{Appendix $\mathbf{J}$}

Climatic and carry-over controls on biomass production for each harvest in the two treatments assessed with simple and multiple regressions (Ecological Archives E095-061-A10).

\section{Appendix K}

Box and whisker plots of the average biomass produced for each harvest in the two treatments (Ecological Archives E095-061-A11).

\section{Appendix L}

Relative abundance of the dominant species in the two treatments at the beginning of the fertilization experiment, in the middle and at the end of the study period (Ecological Archives E095-061-A12). 
Simon Chollet, Serge Rambal, Adeline Fayolle, Daniel Hubert, Didier Foulquié, and Eric Garnier. 2014. Combined effects of climate, resource availability, and plant traits on biomass produced in a Mediterranean rangeland. Ecology 95:736-748.

http://dx.doi.org/10.1890/13-0751.1

Appendix A. Predicted and observed soil water content in the upper $30 \mathrm{~cm}$ from January to December in 2008, together with daily rainfall during the same period.

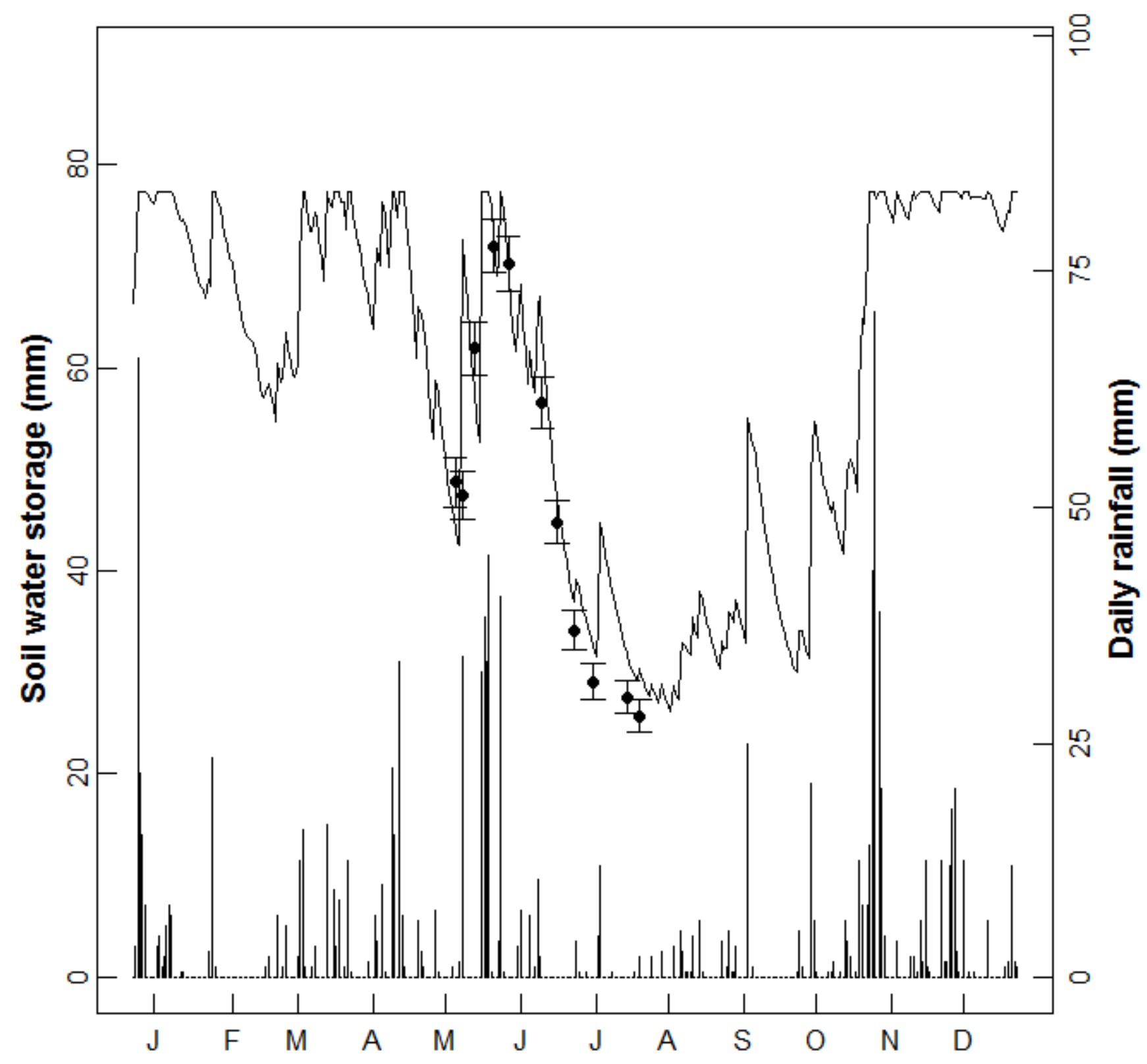

FIG. A1. Predicted soil water content in the upper $30 \mathrm{~cm}$ (solid line) and observed data (dots with bars showing standard deviation) from January to December in 2008. Observed measurements include data from 5 DIVINER 2000-type sensor. Daily rainfall is shown at the bottom of the figure. 


\section{Ecological Archives E095-061-A2}

\section{Simon Chollet, Serge Rambal, Adeline Fayolle, Daniel Hubert, Didier Foulquié, and Eric Garnier.} 2014. Combined effects of climate, resource availability, and plant traits on biomass produced in a Mediterranean rangeland. Ecology 95:736-748. http://dx.doi.org/10.1890/13-0751.1

Appendix B (Table B1). Periods of the year and variables used to assess the abiotic controls on biomass production: relative soil water content (RSWC) and temperature.

\begin{tabular}{|l|c|c|}
\hline Time of harvest & Relative soil water content & Temperature \\
\hline May & $\begin{array}{c}\text { Average of the daily RSWC from 1 } \\
\text { April to 31 May }\end{array}$ & Average of the daily minimum from 1 April to 31 May \\
\hline July & $\begin{array}{c}\text { Average of the daily RSWC from 1 June } \\
\text { to 31 July }\end{array}$ & $\begin{array}{c}\text { Average of the daily maximum from 1 June to 31 July } \\
\text { October }\end{array}$ \\
$\begin{array}{c}\text { Average of the daily RSWC from 1 } \\
\text { August to 31 October }\end{array}$ & $\begin{array}{c}\text { Average of the daily maximum from 1 August to 31 August } \\
\text { + Average of the daily minimum from1 September to 31 } \\
\text { October }\end{array}$ \\
\hline
\end{tabular}

[Back to E095-061] 
Simon Chollet, Serge Rambal, Adeline Fayolle, Daniel Hubert, Didier Foulquié, and Eric Garnier. 2014. Combined effects of climate, resource availability, and plant traits on biomass produced in a Mediterranean rangeland. Ecology 95:736-748. http://dx.doi.org/10.1890/13-0751.1

Appendix C. List of species on which traits were measured, together with their botanical family and life cycle.

TABLE C1. List of species on which traits were measured, together with their botanical family and life cycle. The two last columns indicate the treatment in which traits were measured for each species (GF-: grazed unfertilized; GF+: grazed fertilized: see Appendix L for changes in abundance of the most abundant species over time). Nomenclature follows Euro+Med checklist (http://ww2.bgbm.org/EuroPlusMed/).

\begin{tabular}{|l|l|l|l|l|}
\hline Species & Family & Life cycle & GF- & GF + \\
\hline Achillea millefolium & Asteraceae & Perennial & & $\mathrm{X}$ \\
\hline Alyssum alyssoides & Brassicaceae & Annual & $\mathrm{X}$ & $\mathrm{X}$ \\
\hline Anthyllis montana & Fabaceae & Perennial & $\mathrm{X}$ & \\
\hline Anthyllis vulneraria & Fabaceae & Annual & $\mathrm{X}$ & $\mathrm{X}$ \\
\hline Aphanes arvensis & Rosaceae & Annual & & $\mathrm{X}$ \\
\hline Aphyllanthes monspeliensis & Liliaceae & Perennial & $\mathrm{X}$ & $\mathrm{X}$ \\
\hline Arenaria serpyllifolia & Caryophyllaceae & Annual & $\mathrm{X}$ & $\mathrm{X}$ \\
\hline Bellis perennis & Poaceae & Perennial & $\mathrm{X}$ & $\mathrm{X}$ \\
\hline Brachypodium pinnatum & Psteraceae & Perennial & $\mathrm{X}$ & \\
\hline Briza media & Poaceae & Perennial & $\mathrm{X}$ & \\
\hline Bromus hordeaceus & Annual & & $\mathrm{X}$ \\
\hline
\end{tabular}




\begin{tabular}{|c|c|c|c|c|}
\hline Capsella bursa-pastoris & Brassicaceae & Annual & & $\mathrm{X}$ \\
\hline Carduus nutans & Asteraceae & Perennial & $\mathrm{X}$ & $\mathrm{X}$ \\
\hline Carex flacca & Cyperaceae & Perennial & $\mathrm{X}$ & \\
\hline Carex halleriana & Сyperaceae & Perennial & $\mathrm{X}$ & \\
\hline Carex humilis & Cyperaceae & Perennial & $\mathrm{X}$ & \\
\hline Carlina vulgaris & Asteraceae & Perennial & $\mathrm{X}$ & \\
\hline Carthamus mitissimus & Asteraceae & Perennial & $\mathrm{X}$ & $\mathrm{X}$ \\
\hline Cerastium pumilum & Caryophyllaceae & Annual & $\mathrm{X}$ & $\mathrm{X}$ \\
\hline Coronilla minima & Fabaceae & Perennial & $\mathrm{X}$ & \\
\hline Crepis vesicaria subsp. haenseleri & Asteraceae & Perennial & $\mathrm{X}$ & $\mathrm{X}$ \\
\hline Dactylis glomereta subsp. hispanica & Poaceae & Perennial & $\mathrm{X}$ & \\
\hline Erodium cicutarium & Geraniaceae & Annual & & $\mathrm{X}$ \\
\hline Erophila verna & Brassicaceae & Annual & & $\mathrm{X}$ \\
\hline Eryngium campestre & Apiaceae & Perennial & $\mathrm{X}$ & $\mathrm{X}$ \\
\hline Festuca christiani-bernardii & Poaceae & Perennial & $\mathrm{X}$ & \\
\hline Festuca rubra & Poaceae & Perennial & & $\mathrm{X}$ \\
\hline Filago pyramidata & Asteraceae & Annual & $\mathrm{X}$ & $\mathrm{X}$ \\
\hline
\end{tabular}




\begin{tabular}{|c|c|c|c|c|}
\hline Filipendula vulgaris & |Rosaceae & |Perennial & $\mathrm{X}$ & \\
\hline Galium corrudifolium & Rubiaceae & Perennial & $\mathrm{X}$ & $\mathrm{X}$ \\
\hline Genista hispanica & Fabaceae & Perennial & $\mathrm{X}$ & \\
\hline Geranium dissectum & Geraniaceae & Annual & & $\mathrm{X}$ \\
\hline Geranium rotundifolium & Geraniaceae & Annual & & $\mathrm{X}$ \\
\hline Globularia vulgaris & Globulariaceae & Perennial & $\mathrm{X}$ & \\
\hline Helianthemum apenninum & Cistaceae & Perennial & $\mathrm{x}$ & \\
\hline Helianthemum canum & Cistaceae & Perennial & $\mathrm{X}$ & \\
\hline Helianthemum nummularium & Cistaceae & Perennial & $\mathrm{X}$ & \\
\hline Hieracium pilosella & Asteraceae & Perennial & $\mathrm{X}$ & \\
\hline Hippocrepis comosa & Fabaceae & Perennial & $\mathrm{X}$ & \\
\hline Hordeum murinum & Poaceae & Annual & & $\mathrm{X}$ \\
\hline Koeleria vallesiana & Poaceae & Perennial & $\mathrm{X}$ & $\mathrm{X}$ \\
\hline Lamium amplexicaule & Lamiaceae & Annual & $\mathrm{X}$ & \\
\hline Linum tenuifolium subsp. tenuifolium & Linaceae & Perennial & $\mathrm{X}$ & \\
\hline Lotus corniculatus & Fabaceae & Perennial & $\mathrm{X}$ & \\
\hline Medicago minima & Fabaceae & Annual & & $\mathrm{X}$ \\
\hline Muscari neglectum & Liliaceae & Perennial & & $\mathrm{X}$ \\
\hline
\end{tabular}




\begin{tabular}{|c|c|c|c|c|}
\hline Myosotis ramosissima subsp. ramosissima & Boraginaceae & Annual & $\mathrm{X}$ & $\mathrm{X}$ \\
\hline Ononis striata & Fabaceae & Perennial & $\mathrm{X}$ & \\
\hline Ornithogalum collinum & Liliaceae & Perennial & $\mathrm{X}$ & $\mathrm{X}$ \\
\hline Phleum pratense & Poaceae & Perennial & & $\mathrm{X}$ \\
\hline Plantago lanceolata & Plantaginaceae & Perennial & $\mathrm{X}$ & \\
\hline Plantago media & Plantaginaceae & Perennial & & $\mathrm{X}$ \\
\hline Poa bulbosa & Poaceae & Perennial & $\mathrm{X}$ & $\mathrm{X}$ \\
\hline Poa pratensis & Poaceae & Perennial & & $\mathrm{X}$ \\
\hline Poa trivialis & Poaceae & Perennial & & $\mathrm{X}$ \\
\hline Polygala calcarea & Polygonaceae & Perennial & $\mathrm{X}$ & \\
\hline Potentilla neumanniana & Rosaceae & Perennial & $\mathrm{X}$ & $\mathrm{X}$ \\
\hline Ranunculus bulbosus & Ranunculaceae & Perennial & $\mathrm{X}$ & \\
\hline Salvia pratensis & Lamiaceae & Perennial & $\mathrm{X}$ & $\mathrm{X}$ \\
\hline Sanguisorba minor & Rosaceae & Perennial & $\mathrm{X}$ & $\mathrm{X}$ \\
\hline Seseli montanum & Apiaceae & Perennial & $\mathrm{X}$ & $\mathrm{X}$ \\
\hline Sherardia arvensis & Rubiaceae & Annual & $\mathrm{X}$ & $\mathrm{X}$ \\
\hline Stellaria media & Caryophyllaceae & Annual & & $\mathrm{X}$ \\
\hline & & & & \\
\hline
\end{tabular}




\begin{tabular}{|c|c|c|c|c|}
\hline Stipa pennata & Poaceae & Perennial & $\mathrm{X}$ & \\
\hline Taraxacum laevigatum & Asteraceae & Perennial & $\mathrm{X}$ & $\mathrm{X}$ \\
\hline Taraxacum officinale & Asteraceae & Perennial & & $\mathrm{X}$ \\
\hline Teucrium chamaedrys & Lamiaceae & Perennial & $X$ & \\
\hline Teucrium montanum & Lamiaceae & Perennial & $\mathrm{X}$ & \\
\hline Thymus serpyllum & Lamiaceae & Perennial & $\mathrm{X}$ & $\mathrm{X}$ \\
\hline Trifolium campestre & Fabaceae & Annual & $X$ & $\mathrm{X}$ \\
\hline Trifolium incarnatum & Fabaceae & Annual & & $\mathrm{X}$ \\
\hline Trifolium repens & Fabaceae & Perennial & & $\mathrm{X}$ \\
\hline Trifolium scabrum & Fabaceae & Annual & & $\mathrm{X}$ \\
\hline Veronica arvensis & Scrophulariaceae & Annual & $\mathrm{X}$ & $\mathrm{X}$ \\
\hline Vicia sativa subsp. sativa & Fabaceae & Annual & & $\mathrm{X}$ \\
\hline Vicia tetrasperma subsp. gracilis & Fabaceae & Annual & $\mathrm{X}$ & \\
\hline Vulpia myuros & Poaceae & Annual & & $\mathrm{X}$ \\
\hline
\end{tabular}

[Back to E095-061] 
Simon Chollet, Serge Rambal, Adeline Fayolle, Daniel Hubert, Didier Foulquié, and Eric Garnier. 2014. Combined effects of climate, resource availability, and plant traits on biomass produced in a Mediterranean rangeland. Ecology 95:736-748.

\section{http://dx.doi.org/10.1890/13-0751.1}

Appendix D. Comparison of community-weighted means for Axis1, leaf dry matter content, and reproductive height calculated with traits value measured in the two treatments.
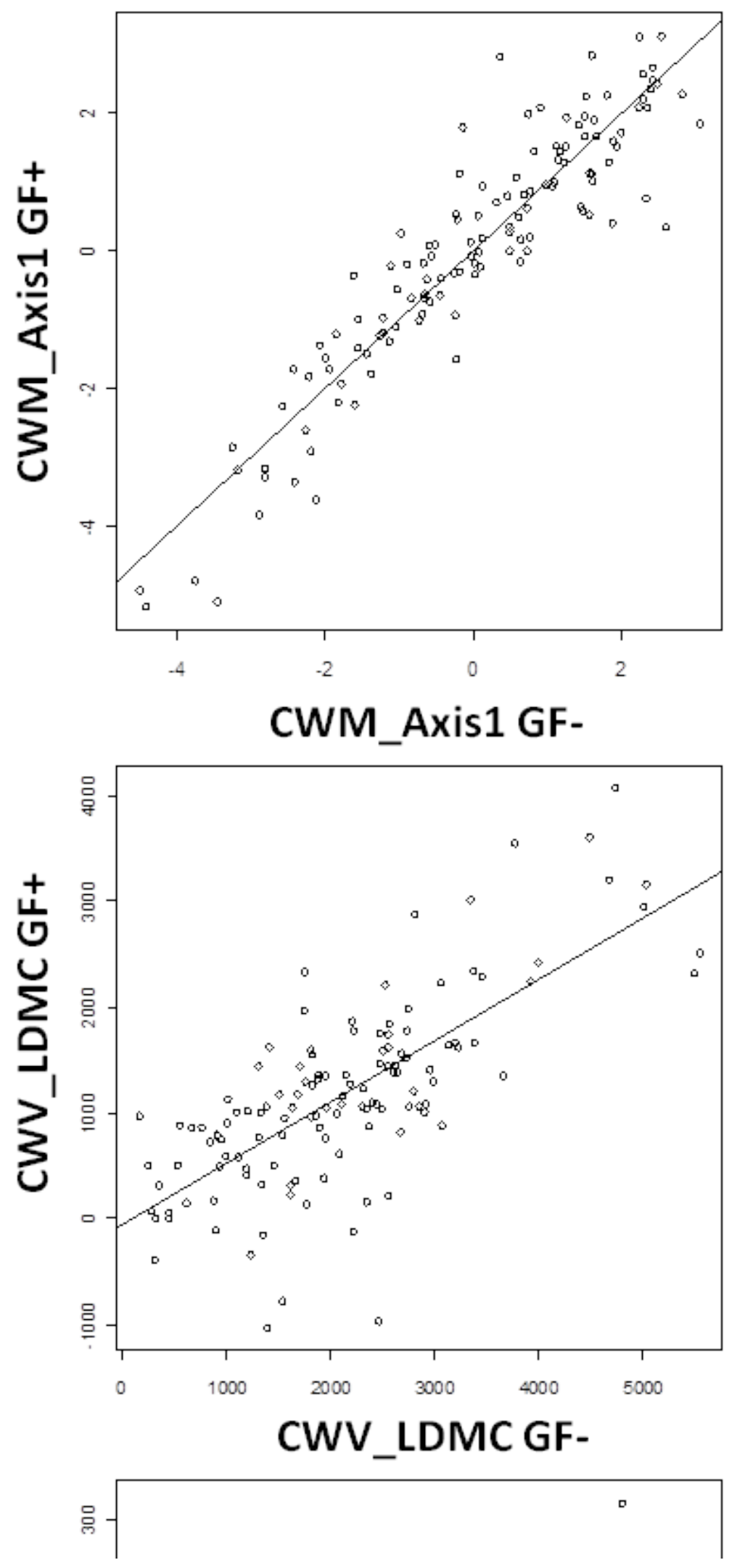


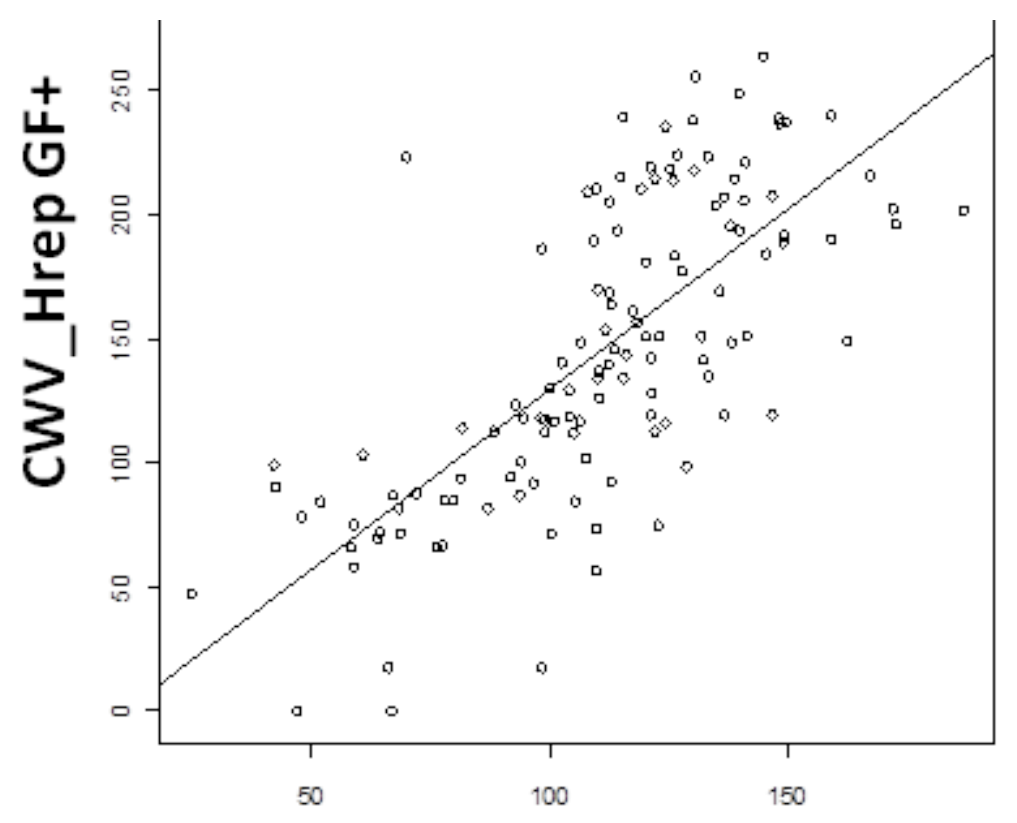

CWV_Hrep GF-

FIg. D1. Comparison of CWM_Axis1, CWV_LDMC and CWV_Hrep calculated with traits value measured in GF+ and GF- (see Material and Methods section for details). All relationship are significant, (a) CWM_Axis1 $R^{2}=0.85$ $P<0.0001$; (b) CWV_LDMC $R^{2}=0.53 P<0.0001$; (c) CWV_Hrep $R^{2}=0.54 P<0.0001$.

[Back to E095-061] 
Simon Chollet, Serge Rambal, Adeline Fayolle, Daniel Hubert, Didier Foulquié, and Eric Garnier. 2014. Combined effects of climate, resource availability, and plant traits on biomass produced in a Mediterranean rangeland. Ecology 95:736-748.

\section{http://dx.doi.org/10.1890/13-0751.1}

Appendix E (TABle E1). Results of Ljung-Box tests to investigate the autocorrelation structure in residuals of the models used in multiple regressions. Residuals of individual regressions have also been tested but results are not shown.

\begin{tabular}{|c|c|c|}
\hline & Ljung-Box & $p$ value \\
\hline May & & \\
\hline M stepAIC & 0.32 & $p=0.57$ \\
\hline M total & 0.72 & $p=0.40$ \\
\hline M climatic & 0.96 & $p=0.32$ \\
\hline M functional & 0.14 & $p=0.71$ \\
\hline July & & \\
\hline M stepAIC & 0.25 & $p=0.61$ \\
\hline M total & 0.003 & $p=0.96$ \\
\hline M climatic & 3.0 & $p=0.08$ \\
\hline M functional & 0.71 & $p=0.39$ \\
\hline October & & \\
\hline M stepAIC & 0.06 & $p=0.80$ \\
\hline
\end{tabular}




\begin{tabular}{|l|c|c|} 
M total & 0.24 & $p=0.62$ \\
\hline M climatic & 2.39 & $p=0.12$ \\
\hline M functional & 0.008 & $p=0.92$ \\
\hline
\end{tabular}

[Back to E095-061] 
Simon Chollet, Serge Rambal, Adeline Fayolle, Daniel Hubert, Didier Foulquié, and Eric Garnier. 2014. Combined effects of climate, resource availability, and plant traits on biomass produced in a Mediterranean rangeland. Ecology 95:736-748. http://dx.doi.org/10.1890/13-0751.1

ApPENDIX F. AIC table for the candidate multiple regression models.

TABLE F1. AIC table for the candidate multiple regression models. M stepAIC: model selected by the stepwise procedure. $\mathrm{M}$ total: model with all parameters (abiotic and biotic). $\mathrm{M}$ climatic: model with climatic factors only. $\mathrm{M}$ functional: model with functional factors only. AICc is the Akaike Information Criterion for small sample sizes, AIC is the Akaike Information Criterion, dAIC is the difference in AIC compared with the best model, and Weight is the Akaike weight (an absolute measure of support that sums to 1 across all candidate models).

\begin{tabular}{|c|c|c|c|c|}
\hline & AICc & AIC & d AIC & Weight \\
\hline May & & & & \\
\hline M stepAIC & 399.6 & 394.7 & 0.0 & 0.914 \\
\hline M total & 412 & 399.8 & 5.1 & 0.071 \\
\hline M climatic & 405.9 & 403.8 & 9.1 & 0.009 \\
\hline M functional & 406.2 & 405.5 & 10.8 & 0.004 \\
\hline July & & & & \\
\hline M stepAIC & 326 & 333.6 & 0.0 & 0.8551 \\
\hline M total & 341 & 337.8 & 4.2 & 0.1043 \\
\hline M climatic & 327.5 & 339.7 & 6.1 & 0.0406 \\
\hline M functional & 358.2 & 364.5 & 30.9 & $<0.001$ \\
\hline October & & & & \\
\hline & & & & \\
\hline
\end{tabular}




\begin{tabular}{|l|l|l|l|l|}
\hline M stepAIC & 339.2 & 338.0 & 0.0 & 0.86732 \\
\hline M total & 353.4 & 341.8 & 3.8 & 0.12922 \\
\hline M climatic & 347.5 & 349.0 & 11.1 & 0.00346 \\
\hline M functional & 355.6 & 361.7 & 23.8 & $<0.001$ \\
\hline
\end{tabular}

[Back to E095-061] 
Simon Chollet, Serge Rambal, Adeline Fayolle, Daniel Hubert, Didier Foulquié, and Eric Garnier. 2014. Combined effects of climate, resource availability, and plant traits on biomass produced in a Mediterranean rangeland. Ecology 95:736-748. http://dx.doi.org/10.1890/13-0751.1

Appendix G. Trait ordination shown in the factorial plan 1-2 of the principal component analysis (PCA) performed on the community-weighted means matrix using data from the two treatments.
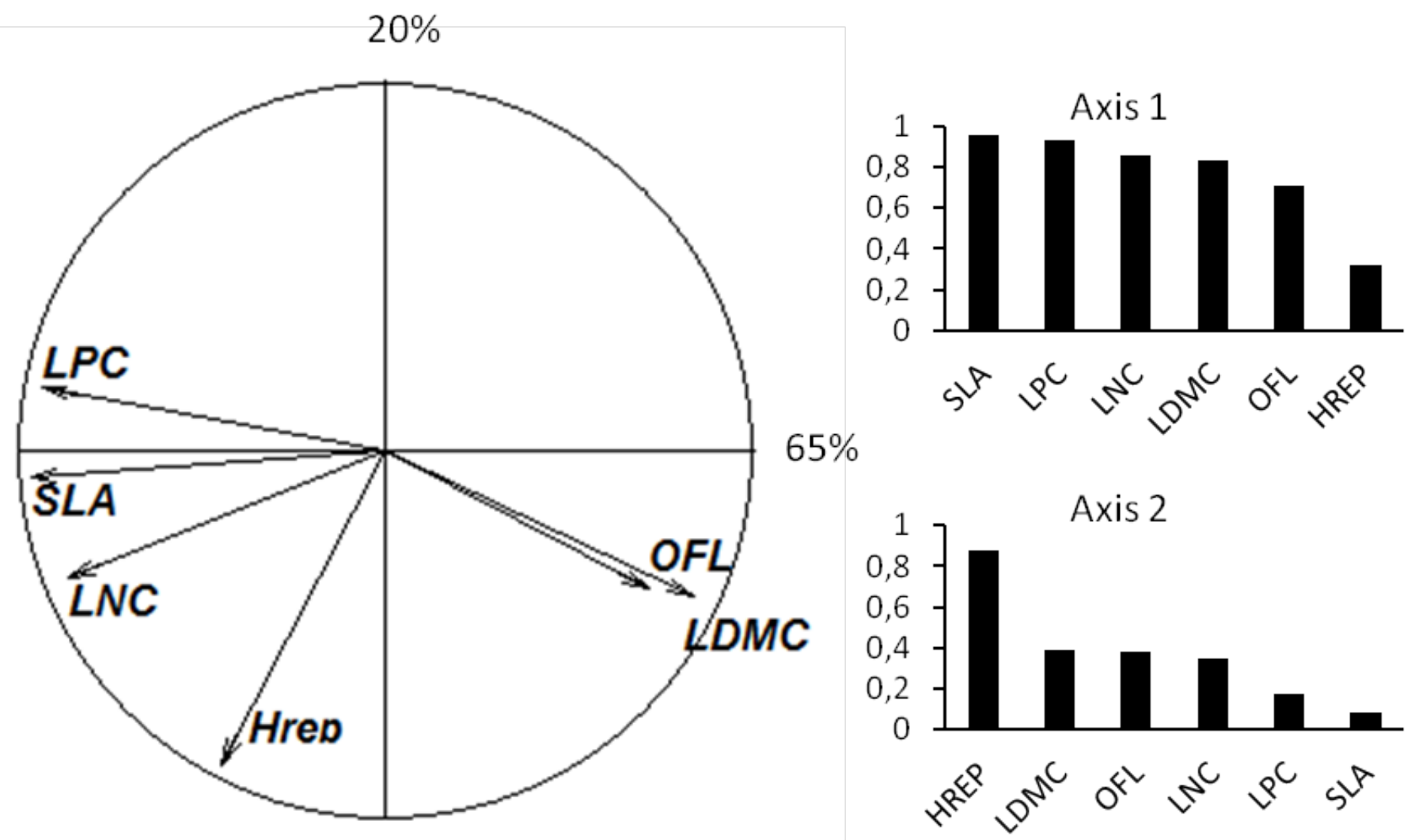

FIG. G1. Trait ordination shown in the factorial plan 1-2 of the principal component analysis performed on the CWM matrix based on the 15 yearly transects over the period 1980-2004 in GF+ and on the 11 transects taken in 1980, 1986, 1995, 1999, and 2004 in GF-. Histograms indicate the contribution of each CWM to Axes 1 and 2. Hrep: reproductive plant height; LDMC: leaf dry matter content; LNC: leaf nitrogen concentration; LPC: leaf phosphorus concentration; OFL: onset of flowering; SLA: specific leaf area. 
Simon Chollet, Serge Rambal, Adeline Fayolle, Daniel Hubert, Didier Foulquié, and Eric Garnier. 2014. Combined effects of climate, resource availability, and plant traits on biomass produced in a Mediterranean rangeland. Ecology 95:736-748. http://dx.doi.org/10.1890/13-0751.1

Appendix H. Top panel: trait ordination shown in the factorial plan 1-2 of the principal component analysis performed on the community-weighted means matrix using data from the grazed/fertilized treatment. Bottom panel: temporal changes in Axis 1 of the PCA conducted on community-weighted mean of traits since 1980 in the grazed/fertilized treatment.
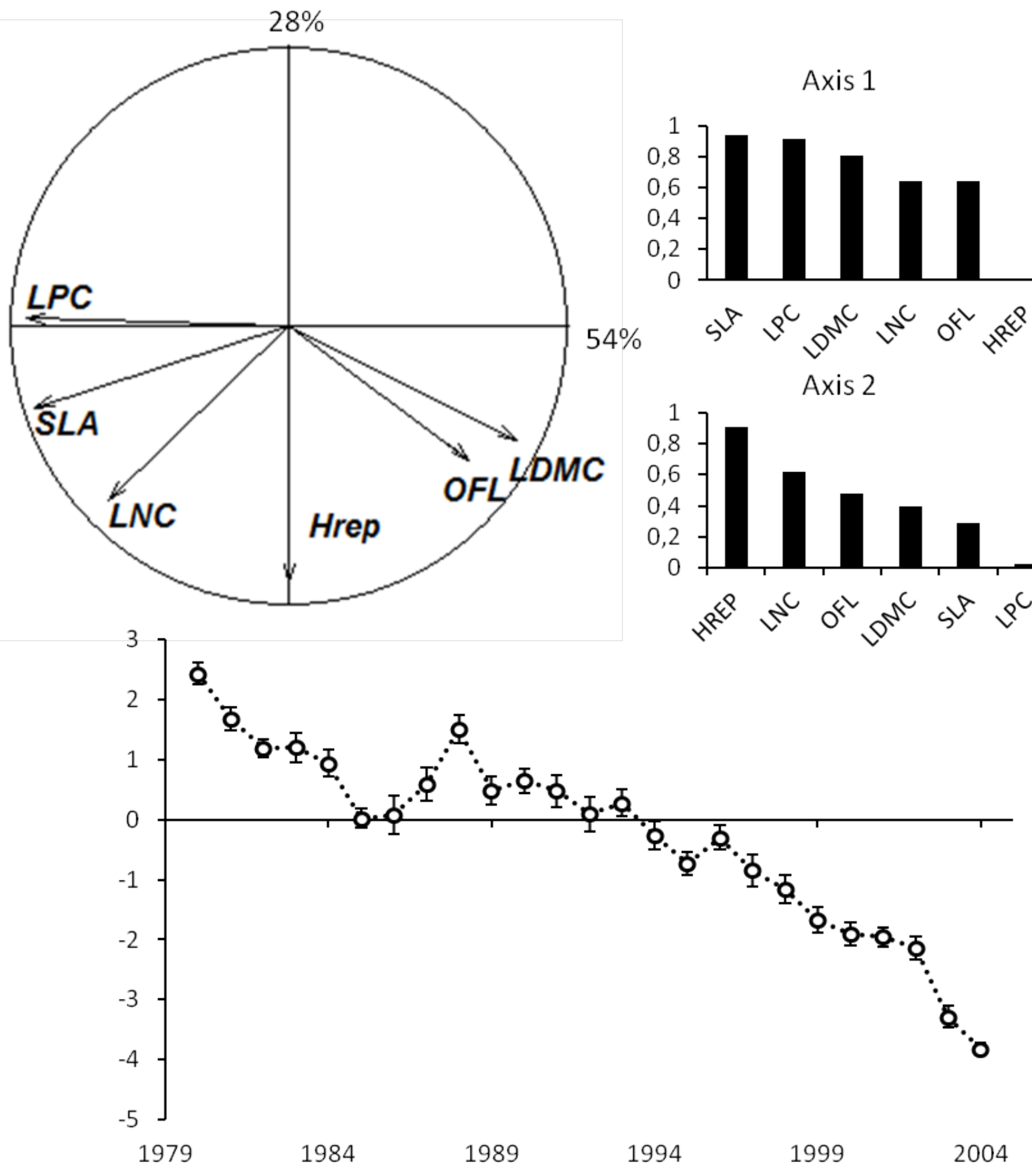

FIG. H1. Top panel: trait ordination shown in the factorial plan 1-2 of the PCA performed on the CWM matrix based on the 15 yearly transects over the period 1980-2004 in GF+ communities. Histograms indicate the contribution of each CWM to Axes 1 and 2. Hrep: reproductive plant height; LDMC: leaf dry matter content; LNC: leaf nitrogen concentration; LPC: leaf phosphorus concentration; OFL: onset of flowering; SLA: specific leaf area. Bottom panel: temporal changes in Axis 1 of the PCA conducted on Community Weighted Mean of traits since 1980 in GF+. Pearson coefficient for the correlation 
Ecological Archives E095-061-A8

between time and Axis 1 is $0.94(P<0.001)$.

[Back to E095-061]

http://www.esapubs.org/archive/ecol/E095/061/appendix-H.php[18/03/2014 09:11:47] 
Simon Chollet, Serge Rambal, Adeline Fayolle, Daniel Hubert, Didier Foulquié, and Eric Garnier. 2014. Combined effects of climate, resource availability, and plant traits on biomass produced in a Mediterranean rangeland. Ecology 95:736-748.

http://dx.doi.org/10.1890/13-0751.1

Appendix I (FIg. I1). Deviation of annual values from the average for the period 1980-2004 for minimal and maximal temperatures, rainfall, and relative soil water content for the La Fage experimental station. 

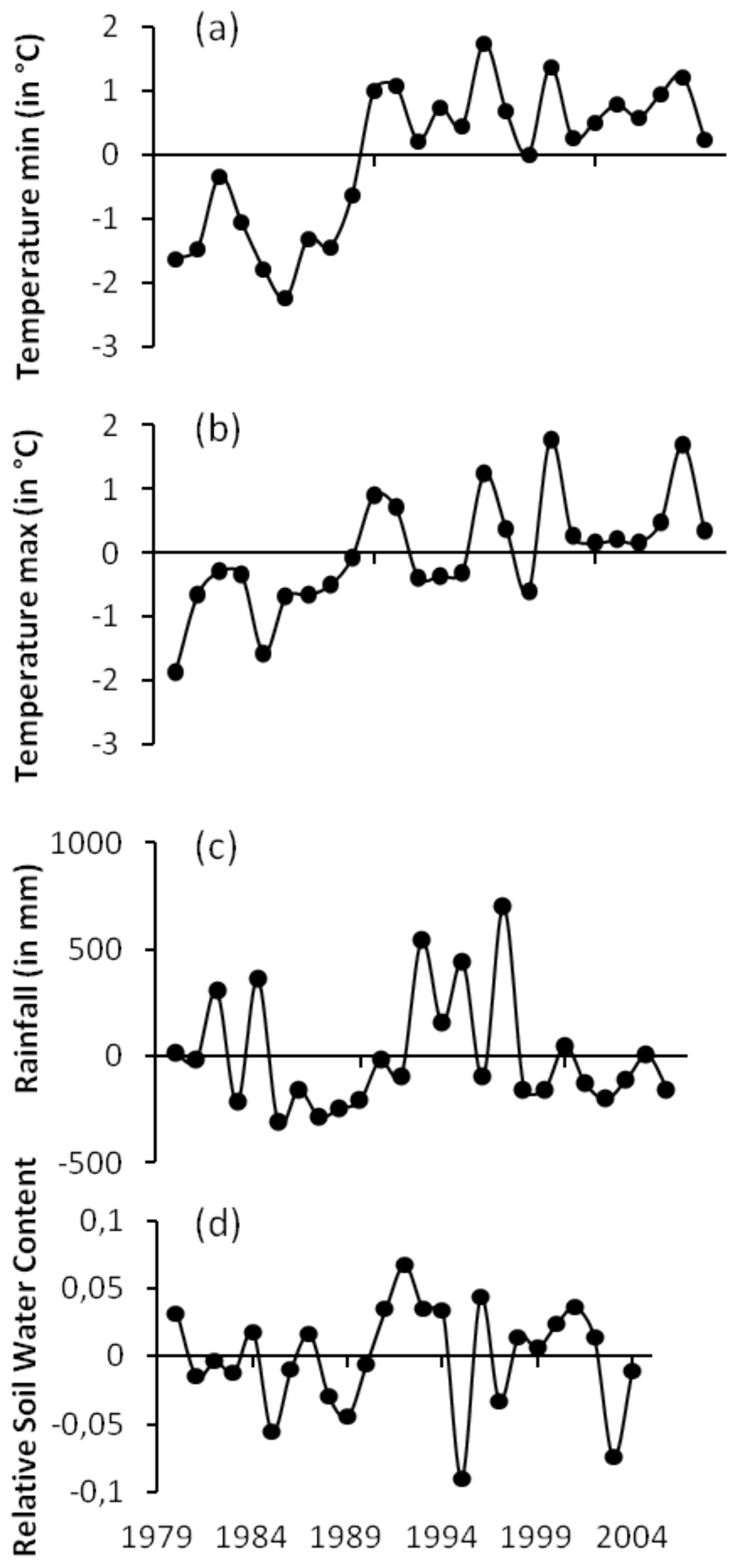

[Back to E095-061] 
Simon Chollet, Serge Rambal, Adeline Fayolle, Daniel Hubert, Didier Foulquié, and Eric Garnier. 2014. Combined effects of climate, resource availability, and plant traits on biomass produced in a Mediterranean rangeland. Ecology 95:736-748. http://dx.doi.org/10.1890/13-0751.1

ApPENDix J. Climatic and carry-over controls on biomass production for each harvest in the two treatments assessed with simple and multiple regressions.

TABLE J1. Climatic and carry-over controls on biomass production for each harvest in GF- and GF+ treatments assessed with simple and multiple ("All factors”) regressions. In the GF+ treatment, the analyses were conducted separately for the 19801991 period (GF1+) on the one hand, and for the 1992-2004 period on the other hand (GF2+): see also Appendix K. The last line gives the coefficient of determination (R2) for each model with its significance level: *: $P<0.05$; **: $P<0.01$; $* * *: P<0.001$. See Table 2 of the main text for abbreviations.

\begin{tabular}{|c|c|c|c|c|c|c|c|c|c|}
\hline \multirow[t]{2}{*}{ Variable } & \multicolumn{3}{|c|}{ May harvest } & \multicolumn{3}{|c|}{ July harvest } & \multicolumn{3}{|c|}{ October harvest } \\
\hline & GF- & GF1+ & GF2+ & GF- & GF1+ & $\mathrm{GF} 2+$ & GF- & GF1+ & GF2+ \\
\hline Tmin & $+0,40 *$ & $+0.50 * *$ & NS & NS & NS & NS & NS & NS & NS \\
\hline Tmax & NS & NS & NS & $-0,49 * *$ & $-0.35^{*}$ & $-0.68 * * *$ & NS & $-0.28(*)$ & $-0.31^{*}$ \\
\hline SW & NS & NS & NS & $+0,72 * * *$ & $+0.40 *$ & $+0.92 * * *$ & NS & $+0.40 *$ & NS \\
\hline N1 & $+0,27 *$ & NS & NS & NS & NS & NS & NS & NS & NS \\
\hline All factors & $\begin{array}{c}\text { Tmin+ } \\
\text { N1 }\end{array}$ & $\begin{array}{c}\text { Tmin }+ \\
\text { N1 }\end{array}$ & NS & RSWC & RSWC & RSWC+Tmax & NS & $\begin{array}{c}\text { RSWC+Tmax } \\
+ \text { Tmin }+\mathrm{N} 1\end{array}$ & $\begin{array}{c}\text { Tmax }+ \\
\text { Tmin }\end{array}$ \\
\hline$R^{2}$ & $0,52 *$ & $0.55^{* *}$ & & $0,72^{* * *}$ & $0.40 *$ & $0.94 * * *$ & & $0.70 *$ & $0.51^{*}$ \\
\hline
\end{tabular}


Simon Chollet, Serge Rambal, Adeline Fayolle, Daniel Hubert, Didier Foulquié, and Eric Garnier. 2014. Combined effects of climate, resource availability, and plant traits on biomass produced in a Mediterranean rangeland. Ecology 95:736-748. http://dx.doi.org/10.1890/13-0751.1

ApPENDIX K. Box and whisker plots of the average biomass produced for each harvest in the two treatments.

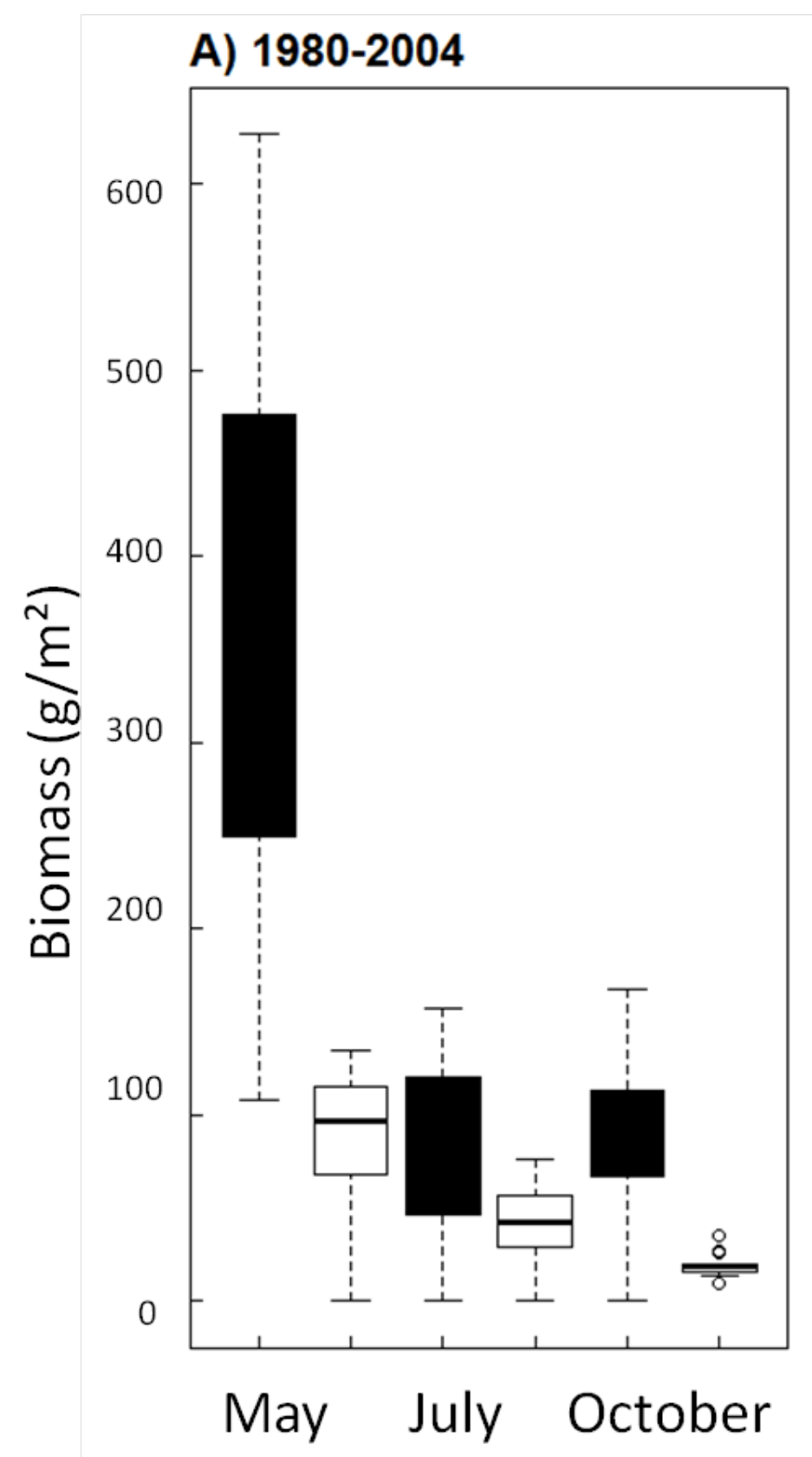

B) 1992-2004

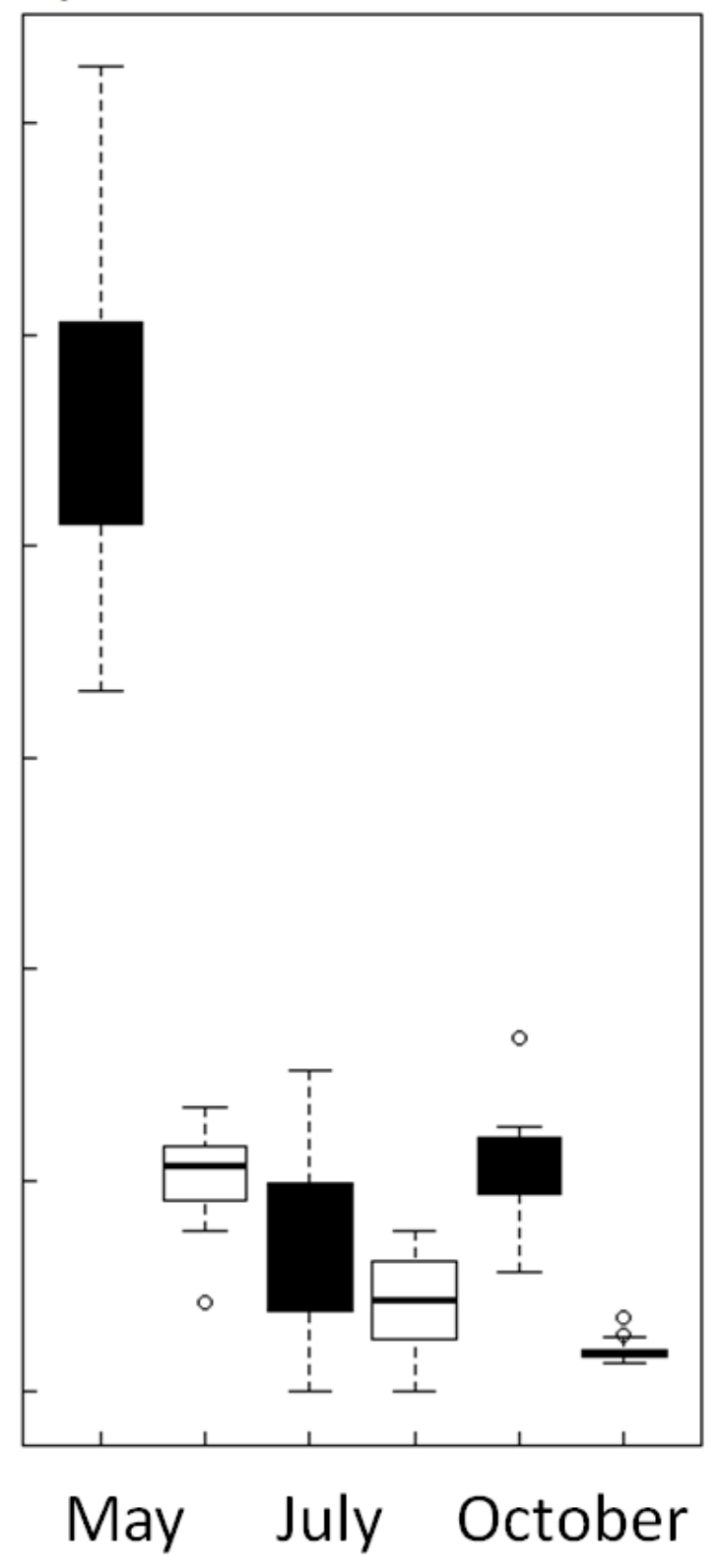

FIG. K1. Box and whisker plots of the average biomass produced for each harvest in the GF+ (black) and GF- (white) treatments. (A) data for the whole period of study: 1980 to 2004 for GF+ and 1990 to 2004 for GF-; B) data for the second period of study only, from 1992 to 2004 in the two treatments. 


\section{Ecological Archives E095-061-A12}

Simon Chollet, Serge Rambal, Adeline Fayolle, Daniel Hubert, Didier Foulquié, and Eric Garnier. 2014. Combined effects of climate, resource availability, and plant traits on biomass produced in a Mediterranean rangeland. Ecology 95:736-748. http://dx.doi.org/10.1890/13-0751.1

Appendix L. Relative abundance of the dominant species in the two treatments at the beginning of the fertilization experiment, in the middle and at the end of the study period.

TABLE L1. Relative abundance of the dominant species in the GF- and GF+ treatments at the beginning of the fertilization experiment (1980), in the middle (1992 or 1995) and at the end of the study period (2004). Botanical family and life cycle of the species are also given.

\begin{tabular}{|c|c|c|c|c|c|c|c|c|}
\hline Species & Family & Life cycle & \multicolumn{3}{|c|}{ GF- } & \multicolumn{3}{|c|}{ GF+ } \\
\hline & & & 1981 & 1995 & 2004 & 1981 & 1992 & 2004 \\
\hline Aphyllanthes monspeliensis & Liliaceae & Perennial & 0.05 & 0.06 & 0.04 & 0 & 0 & 0 \\
\hline Brachypodium pinnatum & Poaceae & Perennial & 0.01 & 0.006 & 0 & 0.05 & 0.002 & 0 \\
\hline Bromus erectus & Poaceae & Perennial & 0.1 & 0.2 & 0.17 & 0.4 & 0.51 & 0.09 \\
\hline Bromus hordeaceus & Poaceae & Annual & 0 & 0 & 0 & 0 & 0.002 & 0.19 \\
\hline Carex halleriana & Сурегасеае & Perennial & 0.005 & 0.007 & 0.03 & 0.03 & 0 & 0 \\
\hline Carex humilis & Сyperaceae & Perennial & 0.08 & 0.1 & 0.15 & 0.06 & 0.002 & 0.002 \\
\hline Erodium cicutarium & Geraniaceae & Annual & 0 & 0 & 0 & 0 & 0.003 & 0.04 \\
\hline Festuca christiani-bernardii & Poaceae & Perennial & 0.23 & 0.19 & 0.11 & 0.18 & 0.12 & 0 \\
\hline Geranium rotundifolium & Geraniaceae & Annual & 0 & 0 & 0 & 0 & 0 & 0.05 \\
\hline Helianthemum canum & Cistaceae & Perennial & 0.05 & 0.05 & 0.02 & 0.002 & 0 & 0 \\
\hline Koeleria vallesiana & Poaceae & Perennial & 0.05 & 0.03 & 0.02 & 0.03 & 0.003 & 0 \\
\hline
\end{tabular}




\begin{tabular}{|l|l|l|c|c|c|c|c|c|} 
& & & & & & & \\
\hline Ononis striata & Fabaceae & Perennial & 0.02 & 0.02 & 0.04 & 0.007 & 0 & 0 \\
\hline Poa bulbosa & Poaceae & Perennial & 0 & 0 & 0 & 0 & 0 & 0.07 \\
\hline Stipa pennata & Poaceae & Perennial & 0.15 & 0.1 & 0.1 & 0.005 & 0 & 0 \\
\hline Thymus serpyllum & Lamiaceae & Perennial & 0.06 & 0.07 & 0.05 & 0.03 & 0.007 & 0 \\
\hline Vulpia myuros & Poaceae & Annual & 0 & 0 & 0 & 0 & 0.11 & 0.25 \\
\hline
\end{tabular}

[Back to E095-061] 